\title{
Modeling Great Depressions: The Depression in Finland in the 1990s
}

Juan Carlos Conesa, Timothy J. Kehoe, and Kim J. Ruhl

Finland has experienced spectacular growth during the past century. Figure 1 displays data on real gross domestic product (GDP) per working-age person (15-64 years) over the period 1900-2005. Notice how growth in Finland, which has averaged 2.4 percent per year, has consistently outstripped the trend growth of 2 percent per year of the United States during most of the century. The major interruptions to this growth have been the First World War during 1914-18, the wars with the Soviet Union 1940-45, and two economic depressions, one in the 1930s and the other in the 1990s. Figure 2 provides a comparison of the depression that began in 1929 with the one

Figure 1. Real GDP per working-age person

in Finland, 1900-2005

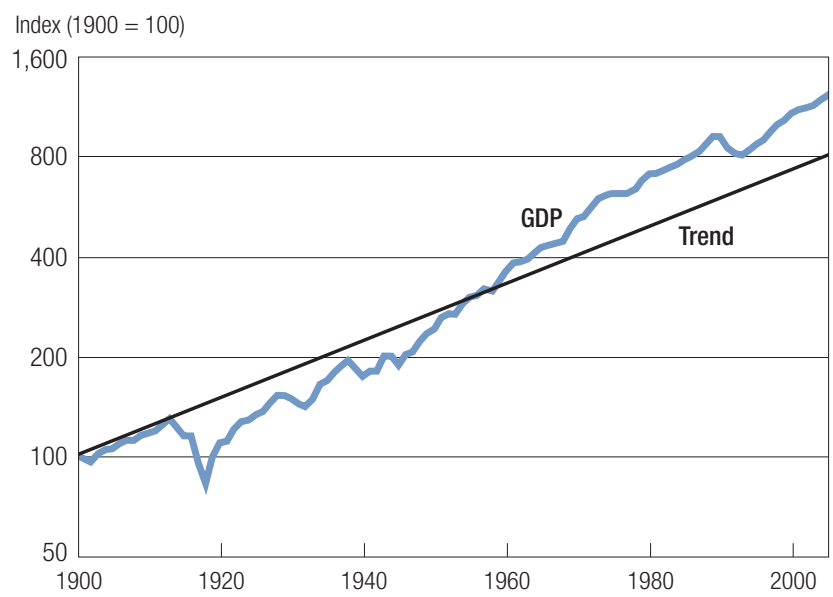


that began in 1990. Neither episode meets the Kehoe-Prescott criteria for a great depression (see the paper in this volume) because real GDP per working-age person detrended by 2 percent per year did not fall by 20 percent. Finnish economists like Kiander and Vartia (1996) refer to both episodes as great depressions, however, and note that the one in the 1990s was the more severe of the two. In Figure 2, it is clear that Finnish economic performance, measured in terms of real GDP per working-age person, was worse in the 1990s than it was in the 1930s.

This paper examines the Finnish depression of the 1990s using the great depressions methodology developed by Cole-Ohanian and Kehoe-Prescott. We start by performing a growth accounting exercise in which we decompose movements in real GDP per working-age person in Finland into movements in total factor productivity (TFP), in hours worked, and in the capital-output ratio. We then develop a simple dynamic general equilibrium model that we use to study the co-movements of macroeconomic variables in Finland over the period 1980-2005. We find that the sharp drop in real GDP over the period 1990-93 was driven by a combination of a drop in TFP during 1990-92 and of an increase in taxes on labor income and on consumption during 1989-94, which drove down hours worked in Finland.

Our results are in accord with those of Böckerman and Kiander (2002b) and Kiander and Vartia (1996), who characterize the causes of the Finnish depression as a combination of "bad luck, bad banking, and bad policy."

Figure 2. Detrended real GDP per working-age person in Finland during the depressions of the 1930s and the 1990s

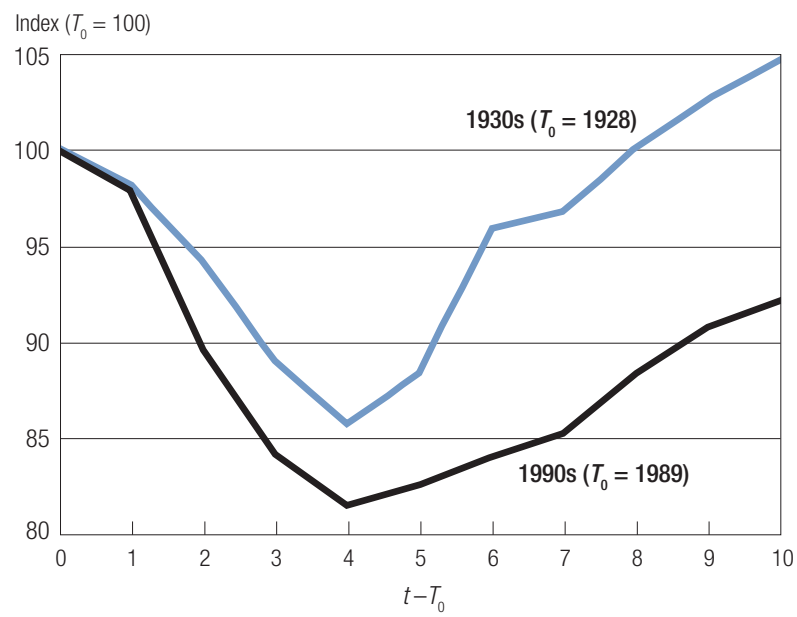


The bad luck refers to the 1989-91 collapse of the Soviet Union, Finland's principal trading partner in 1989; the bad banking refers to the banking crisis in Finland in 1991-94; and the bad policy refers to Finnish labor market policies, in particular, the sharp increase in labor income taxes. Gorodnichenko, Mendoza, and Tesar (2007) also focus on the banking crisis and decline in trade with the Soviet Union as the shocks that generated the depression in Finland. Other references for economic developments in Finland in the 1990s include Böckerman and Kiander (2002a), Kiander (2004), and Koskela and Uusitalo (2004).

Besides providing an analysis of the depression in Finland, this paper is intended to serve as a primer on the use of the great depressions methodology. It explains the growth accounting procedure and presents the base case model used to analyze depression episodes. The base case model, which takes movements in TFP as given, is only partially successful in accounting for the movements in real GDP, hours worked, and capital. The depression in the model is too short and not severe enough. To make the depression in the model last longer and be more severe, we introduce additional features into the model. In particular, we study a version of the model with distortionary taxes and government consumption expenditures, a version of the model in which investment and consumption are produced by different technologies and the relative price of investment relative to consumption fluctuates, and a version of the model in which Finland exports and imports different goods and the price of imports to exports - the terms of trade - fluctuates. We find that only the model with taxes and government consumption is able to significantly improve the performance of the model in accounting for the data. The analyses of the model with investment and the model with trade are useful, however, in showing how to introduce relative price fluctuations into the model.

Even our conclusion that the drop in TFP and the increases in taxes and government consumption, when introduced into the model, can account for the Finnish depression of the 1990s leaves room for future research. The base case model that we present takes the fluctuations in TFP as exogenous. A more successful analysis would model TFP fluctuations as endogenous in the sense that they would be generated by a model in which fluctuations in other variables show up in measured TFP. In all three variants of the base case model - the model with taxes and government consumption, the model with investment, and the model with trade - portions of the fluctuations in TFP are endogenous in the sense that fluctuations in taxes, in the price of investment, and in the terms of trade drive fluctuations in TFP. These models are not successful in capturing the TFP fluctuations observed in the data, however. In fact, we show that, in each of these three models the exogenous fall in 
productivity that we need to enter into the model to explain the observed drop in TFP during the depression is larger than the exogenous fall in TFP in the base case model. That is, each of the three endogenous mechanisms that we introduce into the base case model moves TFP in the wrong direction.

In a more successful model in which TFP fluctuations are endogenous, the crucial elements that drive the fall in TFP during 1990-92 may indeed involve the fluctuations in taxes, the relative price of investment, or the terms of trade. The analysis in this paper indicates some of the difficulties that a more successful analysis will have to overcome.

\section{The Dynamic General Equilibrium Model}

This section presents the simple dynamic general equilibrium model that serves as the base case in our analysis of the Finnish economy. The model features a representative household that chooses paths of consumption, leisure, and investment in order to maximize utility. The household maximizes the utility function

$$
\sum_{t=T_{0}}^{\infty} \beta^{t}\left(\gamma \log C_{t}+(1-\gamma) \log \left(\bar{h} N_{t}-L_{t}\right)\right)
$$

subject to a sequence of budget constraints,

$$
C_{t}+K_{t+1}=w_{t} L_{t}+\left(1-\delta+r_{t}\right) K_{t},
$$

nonnegativity constraints on $C_{t}$ and $I_{t}=K_{t+1}-(1-\delta) K_{t}$, and a constraint on the initial stock of capital, $\bar{K}_{T_{0}}$. In the utility function the parameter $\beta$, $0<\beta<1$, is a discount factor and the parameter $\gamma, 0<\gamma<1$, is a consumption share. Both need to be calibrated. $C_{t}$ is consumption, $K_{t}$ is the capital stock, $L_{t}$ is hours worked, $w_{t}$ is the wage rate, $r_{t}$ is the rental rate, and $\delta$, $0<\delta<1$, is the depreciation rate. The total number of hours available for work is $\bar{h} N_{t}$, where $N_{t}$ is the working-age population and $\bar{h}$ is the number of hours available for market work. We specify $\bar{h}$ as 100 per week. One period of time is one year.

Firms operate in a perfectly competitive market, using a constant returns to scale technology, which we assume to be Cobb-Douglas:

$$
Y_{t}=A_{t} K_{t}^{\alpha} L_{t}^{1-\alpha}
$$

where $Y_{t}$ denotes total output, $A_{t}$ is total factor productivity (TFP), and $\alpha$, $0<\alpha<1$, is the capital share. The conditions that firms earn zero profits and minimize costs provide expressions for the factor prices: 


$$
\begin{aligned}
& w_{t}=(1-\alpha) A_{t} K_{t}^{\alpha} L_{t}^{-\alpha} \\
& r_{t}=\alpha A_{t} K_{t}^{\alpha-1} L_{t}^{1-\alpha} .
\end{aligned}
$$

The current period's output is divided between consumption and investment. The feasibility constraint is

$$
C_{t}+K_{t+1}-(1-\delta) K_{t}=A_{t} K_{t}^{\alpha} L_{t}^{1-\alpha}
$$

\section{The Data}

To perform the growth accounting, we use national accounts data and labor force surveys. For Finland, we use national accounts data constructed using the United Nations' System of National Accounts (SNA93), downloaded from SourceOECD, and data on hours worked per worker, employment rates, and working-age population from the corresponding Labor Force Surveys, also available in the Groningen Growth and Development Center database.

The standard growth accounting is done by the use of an aggregate production function, which is of the Cobb-Douglas form (3). In terms of data, we need measures of output and the capital stock at constant prices and of hours worked. We need to take a stand on what data categories we should be including as investment. We consider the raw measurement of hours worked we use in our analysis as less problematic, although we could choose to weigh hours by some measurement of efficiency units of labor. We also need to calibrate the capital share, $\alpha$.

In the base case model, we assume a closed economy without a government or a foreign sector, and hence the feasibility condition is given by equation (6), which can be written as

$$
C_{t}+I_{t}=Y_{t}
$$

There are several alternative strategies for matching up objects in the model with those in the data. One strategy is to ignore the government and the foreign sector. When following that strategy, $C_{t}$ corresponds to Private Consumption in the national accounts, and $I_{t}$ corresponds to Private Gross Capital Formation. Output is then the sum of these two categories. Notice that this strategy leaves a sizeable fraction of GDP out of the analysis. Another set of strategies - which are followed by the papers in this volume-start by defining $Y_{t}$ to be GDP, and then allocate the categories that are not explicitly considered in the analysis, Government Consumption and Net Exports, to either consumption or investment. The most frequently followed strategy in the papers in this volume is to allocate both categories to consumption. 
Hayashi-Prescott follow an alternative strategy of allocating Government Consumption to consumption but Net Exports to investment, since net exports result in the accumulation of capital abroad. Consistent with this strategy, Hayashi-Prescott define $Y_{t}$ to be gross national product (GNP), rather than GDP. Recall that GNP adds the foreign income of domestic residents to GDP and subtracts the income within the country of foreign residents.

At this point, these alternative strategies for matching up objects in the model with those in the data seem somewhat arbitrary. If one of them produces very different results from another one, it is probably best to develop a model, along with a corresponding accounting procedure, that explicitly takes into account government consumption and/or net exports. We do this later in the paper. Even though we do not do so in this paper, it is worth mentioning that some researchers have found it convenient to consider durable goods consumption as investment. Such an alternative strategy requires us to impute services from durable goods as output. (See, for example, Hansen and Prescott 1995.)

The variables in the feasibility constraint (6) are interpreted as physical units of a homogeneous good, with units measured in values at base period prices. Consequently, we want to measure output and investment at constant prices. The most straightforward procedure is to deflate both consumption and investment with the same deflator, the GDP deflator. It is important to understand that, in the national accounts, this is not the way constant price measures are constructed. There, investment at constant prices is deflated with a different price deflator than is consumption. In fact, Finnish data show a declining trend in the price of investment relative to consumption. In our base case, this declining relative price shows up as capital augmenting technological progress that translates into higher TFP, while the capital stock is measured in units of forgone consumption. Incidentally, increases in the quality of labor, human capital accumulation, and so on would also show up here as increasing TFP. Later, we explore an alternative model in which capital goods are different from consumption goods and can have different prices.

In our analysis, we treat the real variables from the national accounts as though all are measured in prices of the same base period. We later discuss the case where they are chain-weighted quantity indexes.

Standard national accounts, such as those of Finland, do not report a series for the capital stock, so we have to construct such a series using the data on investment. We construct this series using the law of motion for capital in the model,

$$
K_{t+1}=(1-\delta) K_{t}+I_{t} .
$$


This commonly used procedure for calculating a capital stock is referred to as the perpetual inventory method. The inputs necessary to construct the capital stock series are a capital stock at the beginning of the investment series and a value for the constant depreciation rate, $\delta$. The value of $\delta$ is chosen to be consistent with the average ratio of depreciation to GDP observed in the data over the data period used for calibration purposes. For Finland, we find that the ratio of depreciation to GDP over the period 1980-2005 is

$$
\frac{1}{26} \sum_{t=1980}^{2005} \frac{\delta K_{t}}{Y_{t}}=0.1693
$$

Without explicit data on the capital stock at the beginning of the investment series, we have to adopt a more or less arbitrary rule. One rule-the one that we use in this paper-is that the capital-output ratio of the initial period should match the average capital-output ratio over some reference period. Here we choose the capital stock so that the capital-output ratio in 1960 matches its average over 1961-70:

(10) $\frac{K_{1960}}{Y_{1960}}=\frac{1}{10} \sum_{t=1961}^{1970} \frac{K_{t}}{Y_{t}}$.

The system of equations (8)-(10) allows us to use data on investment, $I_{t}$, to solve for the sequence of capital stocks and for the depreciation rate, $\delta$. There are 27 unknowns: $\bar{K}_{1980}, \delta$, and $K_{1981}, K_{1982}, \ldots, K_{2005}$, in 27 equations: 25 equations (8), where $t=1980,1981, \ldots, 2004,(9)$, and (10). Solving this system of equations, we obtain the sequence of capital stocks and a calibrated value for depreciation, $\delta=0.0556$.

An alternative rule to (10) is to choose the initial capital stock so that when we compute the capital stock in the subsequent period using equation (8), its growth rate matches the average growth rate of some number of subsequent periods. If the initial date for the investment series is far removed from the period of time in which we are interested, these different rules have little perceptible effect on our results. In our case, we start our model in 1980, twenty years after the beginning of our capital stock series. With the depreciation rate that we calibrate, this implies that almost 70 percent of the 1960 capital stock has depreciated away by the time the model starts, $0.6815=$ $1-(1-0.0556)^{20}$. By 1989, the year before the start of the depression, this number rises to more than 80 percent.

The last ingredient we need to perform our growth accounting decomposition is to assign a value for the capital share, $\alpha$. We can directly measure 
$\alpha$ from the data, but we need to make some adjustments. If we are using national accounting data under SNA93, as we are in the case of Finland, the income definition of GDP is the sum of three categories: Compensation of Employees, Net Taxes on Production and Imports, and Gross Operating Surplus and Mixed Income. The last category is a residual category. As Gollin (2002) argues, defining the labor income share as the ratio of wages and salaries to GDP at factor prices (excluding indirect taxes) is a bad idea. The problem is that some payments to labor are to self-employed workers and to unremunerated family workers. Furthermore, the fraction of GDP that goes to such workers varies widely from country to country. Consequently, a definition of labor income based exclusively on the wages and salaries included in Compensation of Employees will necessarily be misleading. Correcting the bias in the measurement of factor shares requires constructing some measure of mixed income of the household sector. The Detailed Tables of the National Accounts under SNA93 provide national accounts disaggregated by institutional sectors. Using the Household Sector accounts, we measure nonwage income of the household sector as Gross Operating Surplus and Mixed Income, minus Consumption of Fixed Capital.

We define the labor income share as unambiguous labor income divided by GDP net of the ambiguous categories (household net mixed income and indirect taxes):

$$
\text { Labor Share }=\frac{\text { Compensation of Employees }}{\text { GDP }- \text { Household Net Mixed Income }- \text { Net Indirect Taxes }} .
$$

This procedure is equivalent to splitting the ambiguous categories between labor income and capital income in the same proportions as in the rest of the economy. Our calculations produce an average value of the labor income share of 0.6410 over the period 1980-2005, so that $\alpha=0.3590$.

\section{Growth Accounting}

Once we have obtained measures for output, investment, and hours worked, have constructed a capital stock series, and have calibrated a capital share parameter, we compute TFP:

$$
A_{t}=\frac{Y_{t}}{K_{t}^{\alpha} L_{t}^{1-\alpha}}
$$

The growth accounting that we employ is based on that of HayashiPrescott. To motivate this procedure, suppose that TFP and the working-age population grow at constant rates, 
(13)

$$
\begin{aligned}
& A_{t+1}=g^{1-\alpha} A_{t} \\
& N_{t+1}=n N_{t},
\end{aligned}
$$

where $g^{1-\alpha}-1$ is the growth rate of TFP and $n-1$ is the growth rate of population. Then there is a balanced-growth path in which output per working-age person, $Y_{t} / N_{t}$, grows at the rate $g-1$ and the capital-output ratio, $K_{t} / Y_{t}$, and hours worked per working-age person, $L_{t} / N_{t}$, are constant. That such a path is feasible follows from plugging $A_{t+1}=g^{1-\alpha} A_{t}$ and $K_{t+1} / N_{t+1}=g K_{t} / N_{t}$ into the production function (3),

$$
\frac{Y_{t+1}}{N_{t+1}}=A_{t+1}\left(\frac{K_{t+1}}{N_{t+1}}\right)^{\alpha}\left(\frac{L_{t+1}}{N_{t+1}}\right)^{1-\alpha}=g A_{t}\left(\frac{K_{t}}{N_{t}}\right)^{\alpha}\left(\frac{L_{t}}{N_{t}}\right)^{1-\alpha}=g \frac{Y_{t}}{N_{t}}
$$

Later, we show that there is a unique such path that satisfies the first-order conditions for the representative household's utility maximization problem, and the marginal cost pricing conditions (4) and (5).

We rewrite the production function as

$$
\frac{Y_{t}}{N_{t}}=A_{t}^{\frac{1}{1-\alpha}}\left(\frac{K_{t}}{Y_{t}}\right)^{\frac{\alpha}{1-\alpha}}\left(\frac{L_{t}}{N_{t}}\right)
$$

Notice that, in a balanced-growth path, $\left(K_{t} / Y_{t}\right)^{\alpha /(1-\alpha)}$ and $L_{t} / N_{t}$ are constant, and growth in $Y_{t} / N_{t}$ is driven by growth in $A_{t}^{1 /(1-\alpha)}$. To appreciate the usefulness of this decomposition, consider the data for the United States over the period 1970-2005 graphed in Figure 3. The U.S. growth path is close to balanced: the growth in $Y_{t} / N_{t}$ is close to that in $A_{t}^{1 /(1-\alpha)}$, and $\left(K_{t} / Y_{t}\right)^{\alpha /(1-\alpha)}$ and $L_{t} / N_{t}$ are close to constant. To be sure, there are deviations from balancedgrowth behavior. Over the period 1983-99, output per working-age person $Y_{t} / N_{t}$ rises faster than does the productivity factor $A_{t}^{1 /(1-\alpha)}$, for example, because hours worked per working-age person, $L_{t} / N_{t}$, steadily increase.

Figure 4 depicts the growth accounting for Finland over the same period, 1970-2005. At least three features are worth noting. First, growth in real GDP per working-age person in Finland has been rapid over this period, averaging 2.4 percent per year, compared to 1.7 percent in the United States. Second, the sharp drop in $Y_{t} / N_{t}$ from 1989 to 1992 was driven by both a fall in the productivity factor $A_{t}^{1 /(1-\alpha)}$ and a fall in the labor factor $L_{t} / N_{t}$, but productivity recovered sharply in 1993, and by 1993 it was the fall in labor 
Figure 3. Growth accounting for the United States, 1970-2005

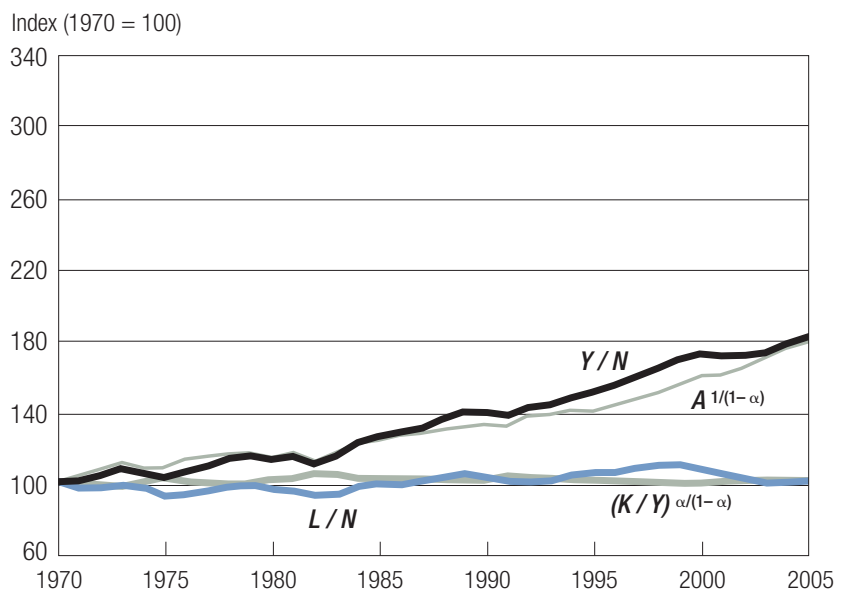

Figure 4. Growth accounting for Finland, 1970-2005

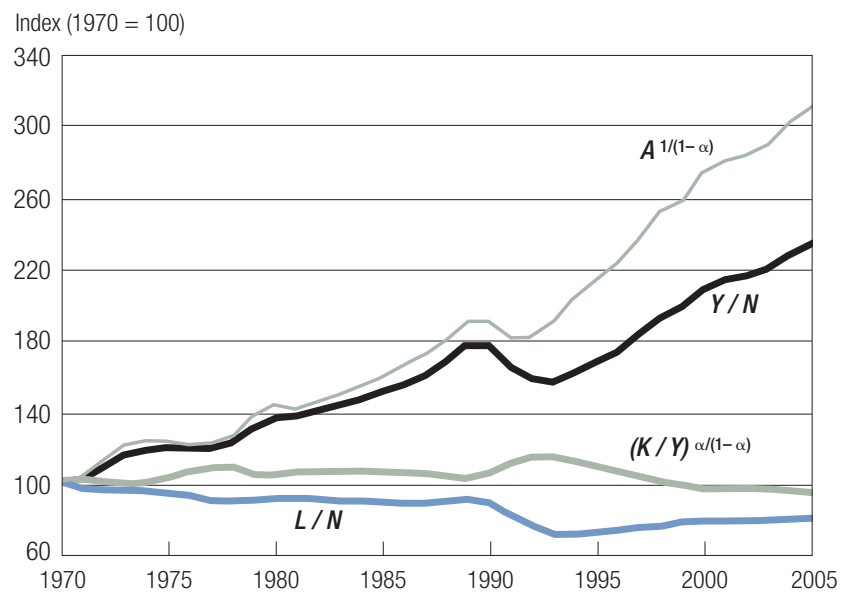

that accounted for all of the drop in output. Over the entire period 1989-93, the fall in hours worked per working-age person of 21.2 percent was far larger than the drop in real GDP per working-age person, 11.8 percent in raw terms and 18.5 percent detrended by 2 percent per year. Third, although output recovered rapidly starting in 1994, labor recovered only partially, and 
hours worked per working-age person in 2005 were still 12.5 percent below their value in 1989. These are the features of the Finnish data that we test our model against, both qualitatively and quantitatively.

\section{Computation of Equilibrium}

In this section we explain how to solve for the model's equilibrium. As we have discussed under "The Dynamic General Equilibrium Model," the model features a representative household that chooses paths of consumption, leisure, and investment to maximize utility. The paths of TFP and population are exogenously given, and the agent has perfect foresight over their values. We start the model at date $T_{0}=1980$ and let time run out to infinity.

Definition. Given sequences of productivity, $A_{t}$, and working-age population, $N_{t}, t=T_{0}, T_{0}+1, \ldots$, and the initial capital stock, $\bar{K}_{T_{0}}$, an equilibrium is sequences of wages, $w_{t}$, interest rates, $r_{t}$, consumption, $C_{t}$, labor, $L_{t}$, and capital stocks, $K_{t}$, such that

1. given the wages and interest rates, the representative household chooses consumption, labor, and capital to maximize the utility function (1) subject to the budget constraints (2), appropriate nonnegativity constraints, and the constraint on $\bar{K}_{T_{0}}$;

2. the wages and interest rates, together with the firms' choices of labor and capital, satisfy the cost minimization and zero profit conditions, (4) and (5); and

3. consumption, labor, and capital satisfy the feasibility condition (6).

We turn these equilibrium conditions into a system of equations that can be solved to find the equilibrium of the model. We begin by taking first-order conditions of the household's problem of maximizing the utility function (1) subject to the budget constraint (2) to obtain

$$
w_{t}\left(\bar{h} N_{t}-L_{t}\right)=\frac{1-\gamma}{\gamma} C_{t}
$$

(18) $\frac{C_{t+1}}{C_{t}}=\beta\left(1-\delta+r_{t+1}\right)$.

Combining the household's optimality conditions (17) and (18), the firm optimality conditions (4) and (5), and the feasibility condition (6), we can specify a system of equations that can be solved to find the equilibrium of the model.

Before explaining how to calculate the whole equilibrium path, let us explain how to calculate a balanced-growth path for this model. 
Definition. Suppose that productivity, $A_{t}$, grows at the constant rate $g^{1-\alpha}-1$ and that working-age population grows at the constant rate $n-1$, then a $b a l$ anced-growth path is levels of the wage, $\hat{w}$, the interest rate, $\hat{r}$, consumption, $\hat{C}$, labor, $\hat{L}$, the capital stock, $\hat{K}$, and output, $\hat{Y}$, such that $w_{t}=g^{t-T_{0}} \hat{w}$, $r_{t}=\hat{r}, C_{t}=(g n)^{t-T_{0}} \hat{C}, L_{t}=n^{t-T_{0}} \hat{L}, K_{t}=(g n)^{t-T_{0}} \hat{K}, Y_{t}=(g n)^{t-T_{0}} \hat{Y}$ satisfy the conditions for an equilibrium when the initial capital stock is $K_{T_{0}}=\hat{K}$.

To solve for the balanced-growth path, we use (5) and (18) to solve for the capital-output ratio $\hat{K} / \hat{Y}$,

$$
g=\beta\left(1+\alpha \frac{\hat{Y}}{\hat{K}}-\delta\right)
$$

We then use (4) and (6) to rewrite (17) as

$$
(1-\alpha)\left(\bar{h} \frac{N_{T_{0}}}{\hat{L}}-1\right)=\frac{1-\gamma}{\gamma}\left(1-(g n-1+\delta) \frac{\hat{K}}{\hat{Y}}\right)
$$

and use this equation to calculate labor, $\hat{L}$. We can then use the production function (3) to solve for $\hat{K}$ and $\hat{Y}$. Using the feasibility condition (6), we can then solve for $\hat{C}$, and, using the firm optimality conditions (4) and (5), we can solve for $\hat{w}$ and $\hat{r}$.

We now return to the calculation of the equilibrium path. Plugging the prices (4) and (5) into the household's optimality conditions (17) and (18), and using the feasibility condition (6), we obtain the system of equations

$$
\begin{aligned}
& (1-\alpha) A_{t} K_{t}^{\alpha} L_{t}^{-\alpha}\left(\bar{h} N_{t}-L_{t}\right)=\frac{1-\gamma}{\gamma} C_{t} \\
& \frac{C_{t+1}}{C_{t}}=\beta\left(1-\delta+\alpha A_{t+1} K_{t+1}^{\alpha-1} L_{t+1}^{1-\alpha}\right) \\
& C_{t}+K_{t+1}-(1-\delta) K_{t}=A_{t} K_{t}^{\alpha} L_{t}^{1-\alpha}
\end{aligned}
$$

Solving for an equilibrium involves choosing sequences of consumption, capital stocks, and hours worked such that these equations are satisfied, given the initial condition $K_{T_{0}}$ and final condition, the transversality condition,

(24) $\lim _{t \rightarrow \infty} \beta^{t} \frac{\gamma}{C_{t}} K_{t+1}=0$. 
In principle, the system of equations that characterize the equilibrium, (21)-(23), involves an infinite number of equations and unknowns. To make the computation of an equilibrium tractable, we assume that the economy converges to the balanced-growth path at some date $T_{1}$, which allows us to truncate the system of equations. Using the feasibility condition (6) to solve for $C_{t}$, we can write these equations as

$$
\begin{aligned}
& (1-\alpha) A_{t} K_{t}^{\alpha} L_{t}^{-\alpha}\left(\bar{h} N_{t}-L_{t}\right)=\frac{1-\gamma}{\gamma}\left(A_{t} K_{t}^{\alpha} L_{t}^{1-\alpha}-K_{t+1}+(1-\delta) K_{t}\right), \\
& t=T_{0}, T_{0}+1, \ldots, T_{1} \\
& \frac{A_{t+1} K_{t+1}^{\alpha} L_{t+1}^{1-\alpha}-K_{t+2}+(1-\delta) K_{t+1}}{A_{t} K_{t}^{\alpha} L_{t}^{1-\alpha}-K_{t+1}+(1-\delta) K_{t}}=\beta\left(1-\delta+\alpha A_{t+1} K_{t+1}^{\alpha-1} L_{t+1}^{1-\alpha}\right), \\
& t=T_{0}, T_{0}+1, \ldots, T_{1}-1,
\end{aligned}
$$

where $K_{T_{1}+1}=g n K_{T_{1}}$.

We choose $T_{1}$ so that $T_{1}-T_{0}$ is large, say 60 , so that we are solving the model over the period 1980-2040. We then construct the exogenous variables. The exogenous variables $A_{t}, N_{t}$ for 1980-2005 are as they are in the data. For 2006-2040, we assume that TFP grows at a constant rate equal to the average growth rate of TFP over the period 1980-2005 and that the workingage population grows at the same rate as in 2004-5. These are the growth rates $g^{1-\alpha}$ and $n$ in the specification of the balanced-growth path.

Solving the model now consists of choosing $K_{T_{0}+1}, K_{T_{0}+2}, \ldots, K_{T_{1}}$, and $L_{T_{0}}, L_{T_{0}+1}, \ldots, L_{T_{1}}$ to solve the system of equations (25) and (26). This system of $2\left(T_{1}-T_{0}\right)-1$ nonlinear equations in $2\left(T_{1}-T_{0}\right)-1$ unknowns can be solved relatively quickly using numerical methods. A set of MATLAB programs for solving this model are available at www.greatdepressionsbook. com. The details of the programs are available in Appendix A.

\section{Calibration and Results for the Base Case Model}

In addition to the exogenous paths for productivity and population, we need to specify the parameters $\beta, \gamma, \delta$, and $\alpha$. We continue to use the values for $\alpha$ and $\delta$ that we calibrated under "The Data." To calibrate a value for $\beta$, we use (22) to write

$$
\beta=\frac{C_{t+1}}{C_{t}\left(1-\delta+\alpha Y_{t+1} / K_{t+1}\right)} .
$$


With values for $\alpha$ and $\delta$, and data on capital, output, and consumption, we compute $\beta$ for each period and take the average over 1970-80. That is, we calibrate household behavior to a period outside that in which we are interested. We find $\beta=0.9752$.

The procedure for calibrating $\gamma$ is similar. We use (21) to write

(28) $\gamma=\frac{C_{t} L_{t}}{Y_{t}\left(\bar{h} N_{t}-L_{t}\right)(1-\alpha)+C_{t} L_{t}}$.

Using data on consumption, hours worked, population, and output and the value for $\alpha$, we find that the average value over $1970-80$ is $\gamma=0.2846$.

We plot the results for the base case model in Figures 5-7. Table $1 \mathrm{com}-$ pares the growth accounting in the model with that in the data. Here we take natural logarithms of equation (16) so that output per working-age person decomposes into three additive factors:

(29) $\log \frac{Y_{t}}{N_{t}}=\frac{1}{1-\alpha} \log A_{t}+\frac{\alpha}{1-\alpha} \log \frac{K_{t}}{Y_{t}}+\log \frac{L_{t}}{N_{t}}$.

The numbers reported in Table 1 are average annual changes multiplied by 100 , which can be interpreted as growth rates. Notice that the model only partially accounts for the fall in output during the depression. From 1989 to

Figure 5. Base case model: Detrended real GDP per working-age person in Finland

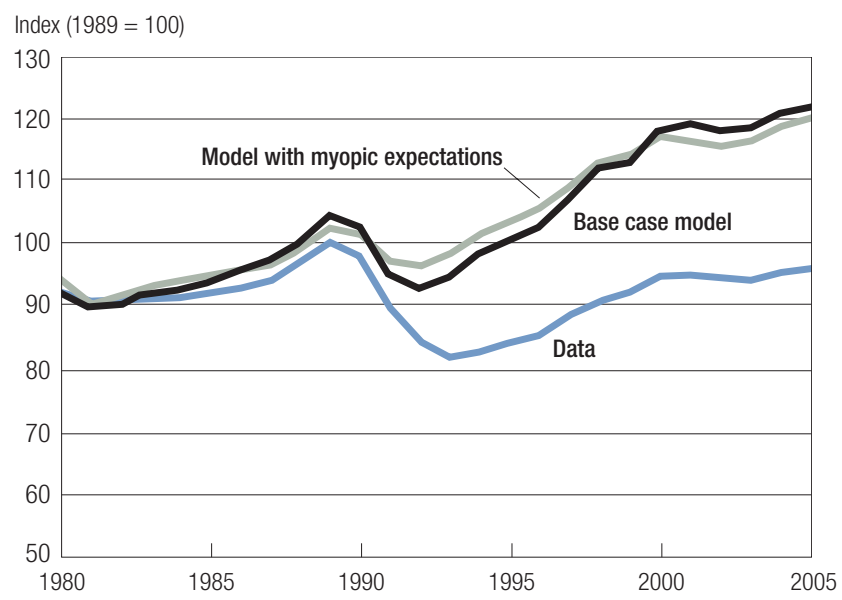


Figure 6. Base case model: Hours worked per working-age person in Finland

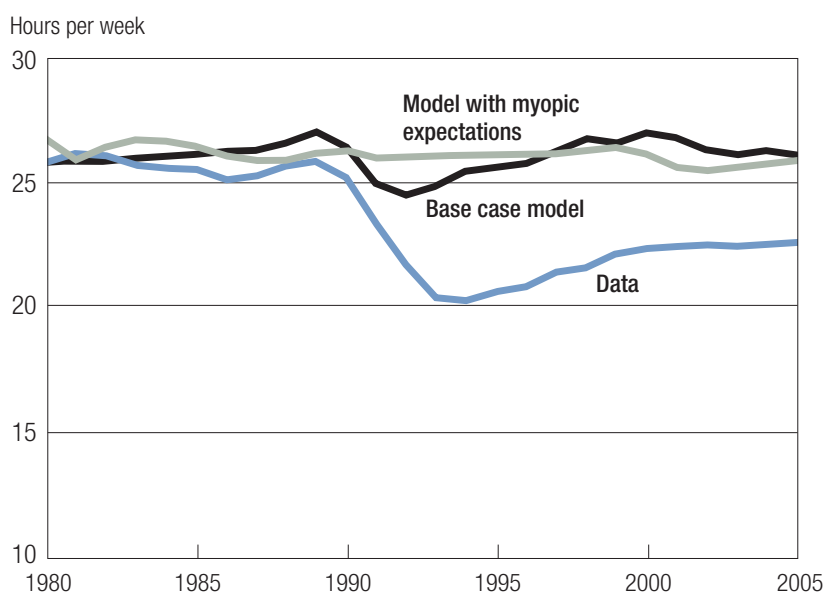

Figure 7. Base case model: Capital-labor ratio in Finland

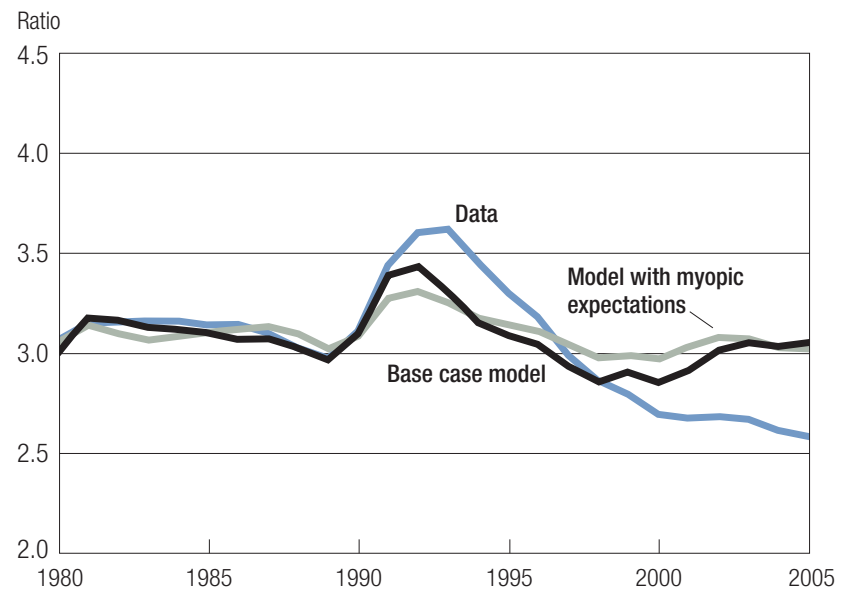

1993, real GDP per working-age person in Finland fell by 11.8 percent, 18.5 percent when detrended by 2 percent per year. In contrast, in the model it falls by only 1.9 percent, 9.4 when detrended. Furthermore, the timing is off. Output was still falling in 1993 in the data, whereas it is rising in the model. Notice too that the model is able to account for only about one-third of the fall in hours worked in the data. 
The base case numerical experiment is nonstochastic in that we assume that households in 1980 have perfect foresight on the evolution of TFP over the next twenty-five years. In the numerical experiment that we call myopic expectations, we assume that households expect TFP in the future to grow at the same rate that it grew over the previous ten years. We impose these same conditions on expectations after 2005. We assume that households have perfect foresight over the evolution of working-age population, however, because they can observe birth rates and project them into the future. This numerical experiment requires us to solve the model twenty-six times, once for each year from 1980 to 2005. In 1989, for example, households expect TFP to grow forever at the same rate that it grew over the period 1979-89. We compute a perfect foresight equilibrium for these expectations. In 1990, households are surprised by a sudden fall in TFP, and they modify their expectations of TFP growth to be that over the period 1980-90.

Notice in Figures 5-7 and Table 1 how similar the results of the numerical experiment with myopic expectations are to those of the base case, where there is perfect foresight, especially with respect to real GDP per working-age person. Where there are deviations between the results with perfect foresight

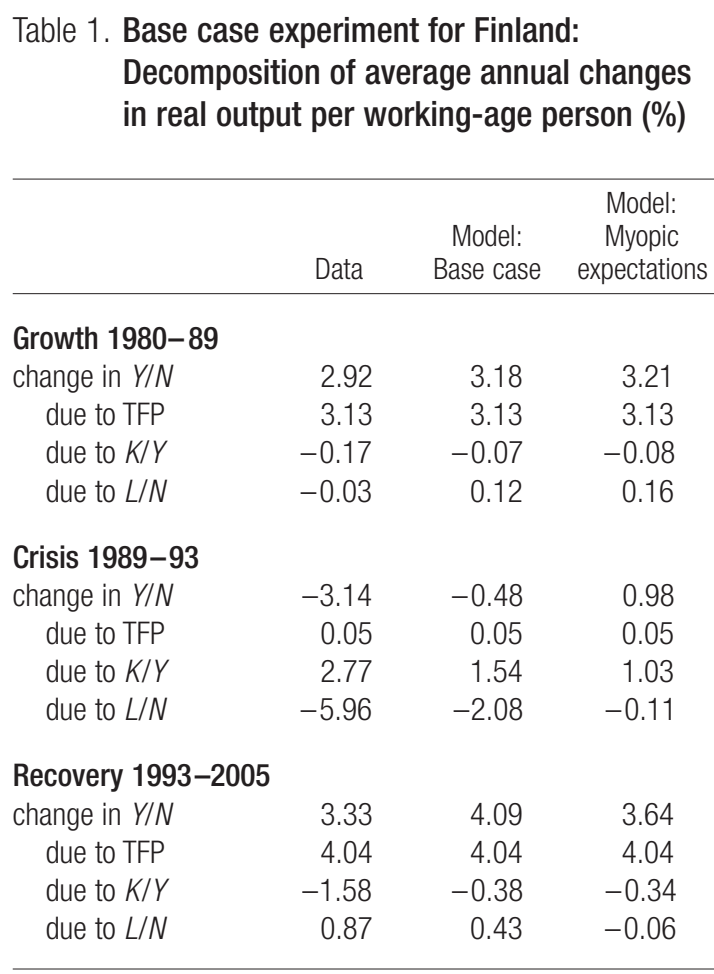


and those with myopic expectations, the results with myopic expectations move the results of the model further from the data. Notice especially in Figure 6 that the model with myopic expectations fails to capture the fall in hours worked during the depression. This is because of the general equilibrium structure of the model. The downturn in Finland during 1989-93 was so short that households did not have time to adjust their expectations of TFP downward and kept up levels of investment. Consequently, because the level of the capital stock is higher during the depression in the model with myopic expectations than it is in the base case model with perfect foresight, real wages, and therefore employment, are also higher.

\section{Taxes and the Role of the Government Sector}

In this section we introduce distortionary taxes and government spending into our model. We find that increases in distortionary taxes generate large declines in hours worked in Finland. The conclusion agrees with that of Böckerman and Kiander (2002a, 2002b) for Finland and is in accord with the results obtained by Conesa and Kehoe (2007), Ohanian, Raffo, and Rogerson (2006), and Prescott (see the paper in this volume) for a number of other countries.

Consider an environment where the government levies distortionary taxes and uses the proceeds to finance transfers to the household sector and government consumption. The representative household's problem is to maximize utility (1) subject to the sequence of budget constraints

$$
\left(1+\tau_{t}^{c}\right) C_{t}+K_{t+1}=\left(1-\tau_{t}^{\ell}\right) w_{t} L_{t}+\left(1+\left(1-\tau_{t}^{k}\right)\left(r_{t}-\delta\right)\right) K_{t}+T_{t},
$$

appropriate nonnegativity constraints, and a constraint on the initial stock of capital, $\bar{K}_{T_{0}}$. Here $\tau_{t}^{c}$ is the tax rate on consumption; $\tau_{t}^{\ell}$ is the marginal tax rate on labor income; $\tau_{t}^{k}$ is the marginal tax rate on capital income; and $T_{t}$ is a lump-sum transfer, which may be positive or negative, received from the government. Notice that the introduction of taxes requires us to modify the first-order conditions (17) and (18) of the representative household:

$$
\begin{aligned}
& \frac{1-\gamma}{\gamma} \frac{C_{t}}{\bar{h} N_{t}-L_{t}}=\frac{1-\tau_{t}^{\ell}}{1+\tau_{t}^{c}}(1-\alpha) A_{t} K_{t}^{\alpha} L_{t}^{-\alpha} \\
& \frac{C_{t+1}}{C_{t}}=\frac{1+\tau_{t}^{c}}{1+\tau_{t+1}^{c}} \beta\left(1+\left(1-\tau_{t+1}^{k}\right)\left(\alpha A_{t+1} K_{t+1}^{\alpha-1} L_{t+1}^{1-\alpha}-\delta\right)\right)
\end{aligned}
$$

The sequence of government budget constraints is 


$$
\tau_{t}^{c} C_{t}+\tau_{t}^{\ell} w_{t} L_{t}+\tau_{t}^{k}\left(r_{t}-\delta\right) K_{t}=G_{t}+T_{t}
$$

where the government finances government consumption, $G_{t}$, and transfers to the household sector $T_{t}$.

We modify the feasibility constraint (6) to include government consumption:

$$
C_{t}+K_{t+1}-(1-\delta) K_{t}+G_{t}=A_{t} K_{t}^{\alpha} L_{t}^{1-\alpha}
$$

Definition. Given sequences of productivity, $A_{t}$, and working-age population, $N_{t}$, consumption taxes, $\tau_{t}^{c}$, labor taxes, $\tau_{t}^{\ell}$, capital taxes, $\tau_{t}^{k}$, and government consumption, $G_{t}, t=T_{0}, T_{0}+1, \ldots$, and the initial capital stock, $\bar{K}_{T_{0}}$, an equilibrium with taxes and government consumption is sequences of wages, $w_{t}$, interest rates, $r_{t}$, consumption, $C_{t}$, labor, $L_{t}$, capital stocks, $K_{t}$, and transfers, $T_{t}$, such that

1. given the wages and interest rates, the representative household chooses consumption, labor, and capital to maximize the utility function (1) subject to the budget constraint (30), appropriate nonnegativity constraints, and the constraint on initial capital $\bar{K}_{T_{0}}$;

2. the wages and interest rates, together with the firms' choices of labor and capital, satisfy the cost minimization and zero profit conditions, (4) and (5);

3. government consumption and transfers satisfy the government budget constraints (33); and

4. consumption, labor, and capital satisfy the feasibility condition (34).

It is worth pointing out that there is an equivalence between this specification and one in which government transfers are exogenously given and the government balances its budget by selling bonds. In this case, the representative household faces the sequence of budget constraints

$$
\begin{aligned}
& \left(1+\tau_{t}^{c}\right) C_{t}+K_{t+1}+B_{t+1} \\
& =\left(1-\tau_{t}^{\ell}\right) w_{t} L_{t}+\left(1+\left(1-\tau_{t}^{k}\right)\left(r_{t}-\delta\right)\right)\left(K_{t}+B_{t}\right)+T_{t},
\end{aligned}
$$

initial conditions on capital, $\bar{K}_{T_{0}}$, and bonds, $\bar{B}_{T_{0}}$, and a constraint of the form $B_{t} \geq-g^{t} B$, where the constant $B>0$ is chosen large enough so that the constraint never binds in equilibrium except to prevent the household from running Ponzi schemes. The government faces the sequence of government budget constraints 


$$
\tau_{t}^{c} C_{t}+\tau_{t}^{\ell} w_{t} L_{t}+\tau_{t}^{k}\left(r_{t}-\delta\right)\left(K_{t}+B_{t}\right)+B_{t+1}=G_{t}+T_{t}+\left(1+r_{t}-\delta\right) B_{t}
$$

and a constraint that says that debt cannot get too large,

$$
\lim _{t \rightarrow \infty} \beta^{t} \frac{\gamma}{C_{t}} B_{t+1} \leq 0
$$

To be precise about the equivalence: For any equilibrium in the model with exogenous transfers and government bonds, $T_{t}$ and $B_{t}$, in which $B_{T_{0}}=0$, there is an equilibrium in the model with endogenous transfers, $\hat{T}_{t}$, and no bonds in which

$$
\hat{T}_{t}=T_{t}+\left(1+r_{t}-\delta\right) B_{t}-\tau_{t}^{k}\left(r_{t}-\delta\right) B_{t}-B_{t+1} .
$$

Conversely, for any equilibrium in the model with endogenous transfers, $T_{t}$, and no bonds, there is an equilibrium in the model with exogenous transfers and government bonds, $\hat{T}_{t}$ and $\hat{B}_{t}$, in which $\hat{T}_{t}=T_{t}$ and $\hat{B}_{t}=0$. Notice that there are actually infinitely many combinations of transfers and bonds that have the same values of all of the other variables in equilibrium as the model with endogenous transfers and no bonds. Unless there is some reason to model government debt or to fix transfers, we therefore use the specification with endogenous transfers and no bonds.

If utility is separable between the consumption-leisure bundle and public goods and services, the distinction between public goods and services and government consumption that is not valued by the household is inconsequential except for welfare measurement. The distinction between government consumption and transfers is more involved, however. We explore the importance of this distinction in the next section.

\section{Calibration and Results for the Model with Taxes and Government Spending}

To obtain estimates of the sequences of effective tax rates $\tau_{t}^{c}, \tau_{t}^{\ell}$, and $\tau_{t}^{k}$, we use data on aggregate tax collections from its main sources-individual and household income taxes, corporate income taxes, sales and excise taxes, payroll taxes, and so on - and classify them according to the tax categories we have in our analysis: consumption tax, labor income tax, and capital income tax. We follow the methodology of Mendoza, Razin, and Tesar (1994), with two main differences. First, since we attribute a fraction of households' nonwage income to labor income, we take that into account when defining the relevant tax base in the data. Second, we set the income tax rates, $\tau_{t}^{\ell}$, and $\tau_{t}^{k}$, equal to their effective marginal rates, as opposed to effective average rates. 


\section{Figure 8. Tax rates in Finland}

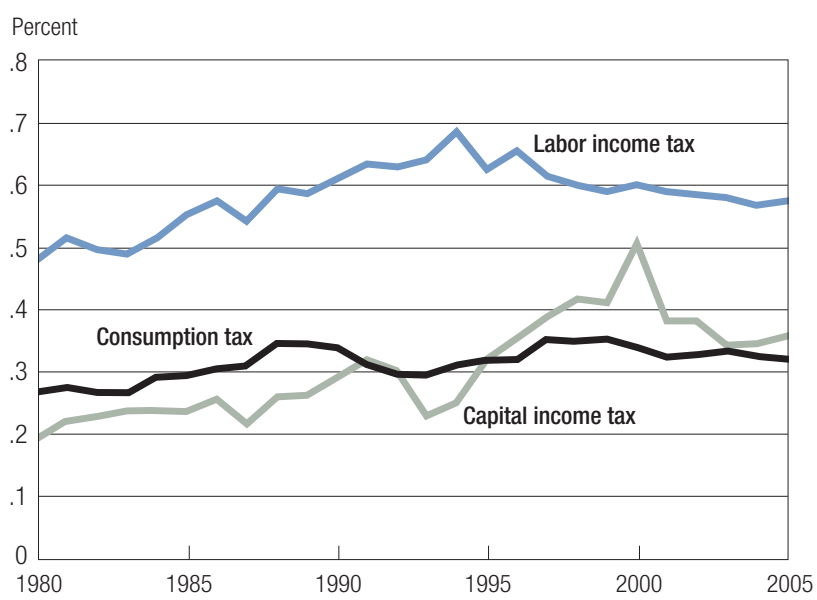

We focus on marginal rather than average effective tax rates because, given our theoretical framework, the relevant household decisions are taken at the margin as in (31) and (32). Notice that our specification of transfers allows us to specify progressive income taxes with constant marginal tax rates. In principle, we need to adjust our income tax estimates using estimated effective income tax functions with disaggregated data. In this paper, we simply follow Prescott (see the paper in this volume) for the U.S. case in multiplying average income taxes by a factor of 1.6 to obtain marginal tax rates. An explicit procedure for calculating the tax rates for Finland is presented in Appendix B. These tax rates are graphed in Figure 8.

We are still left with the nontrivial issue of allocating government revenues between government consumption and transfers. We run numerical experiments of the model under two different specifications. In the first specification, we assume that all government revenues are given as a lumpsum rebate to households. In other words, we set $G_{t}=0$ in (33) and (34). This specification implies that all government revenues go to transfers to the households, such as pensions or unemployment subsidies, or to purchases of goods and services that would otherwise be provided privately, such as education or health care. The alternative specification, which follows Conesa and Kehoe (2007), is to go to the other extreme and assume that government consumption in the national accounts is wasted or that it produced a public good that enters the households' utility function separably. For example, we could specify utility as 


\section{Figure 9. Government consumption in Finland}

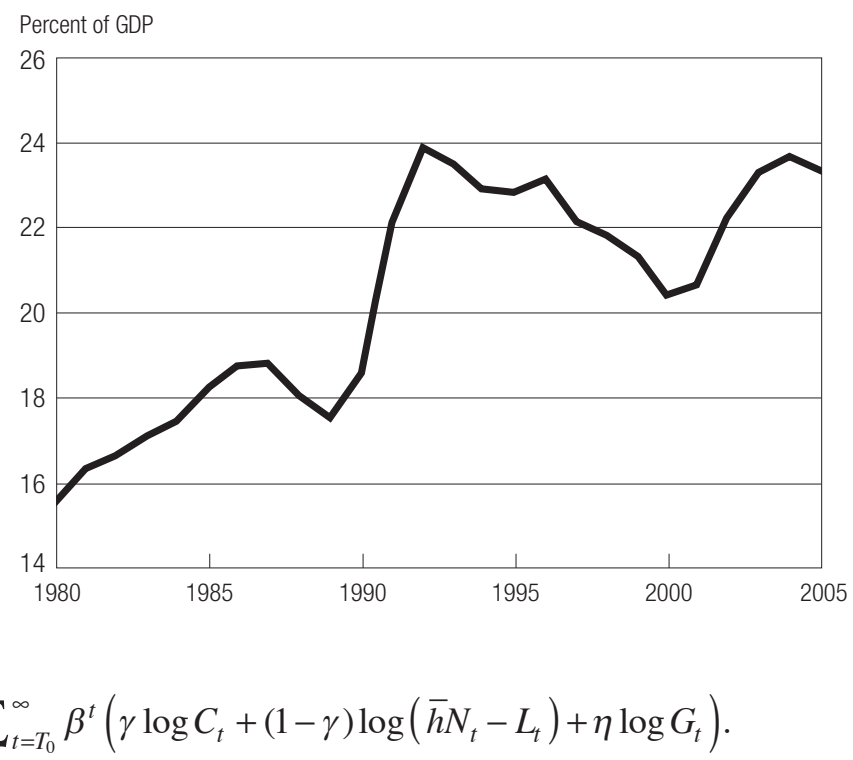

$$
\sum_{t=T_{0}}^{\infty} \beta^{t}\left(\gamma \log C_{t}+(1-\gamma) \log \left(\bar{h} N_{t}-L_{t}\right)+\eta \log G_{t}\right)
$$

Figure 9 shows the data for the evolution of government consumption in Finland.

In the numerical experiments, we assume that government spending grows by the factor $g n$ so that we can assume the equilibrium converges to a balanced-growth path. In the data, government consumption grows faster than this over the period 1980-2005. If we project government consumption as growing at this faster rate into the future, however, it eventually becomes larger than the economy can feasibly supply. The reason for this is easily seen in Figure 9. If we extrapolate the growth in government consumption as a percentage of GDP, government consumption eventually becomes more than 100 percent of GDP.

To exogenously set the productivity series, we modify equation (12),

(40) $A_{t}=\frac{C_{t}+I_{t}}{K_{t}^{1-\alpha} L_{t}^{\alpha}}$

where $C_{t}+I_{t}$ is real GDP at factor prices in the data. When we report the contribution of TFP to growth, however, we calculate TFP as conventionally measured, 
(41) $\hat{A}_{t}=\frac{\hat{Y}_{t}}{K_{t}^{1-\alpha} L_{t}^{\alpha}}$,

where

(42) $\hat{Y}_{t}=\left(1+\tau_{\bar{T}}^{c}\right) C_{t}+I_{t}$

is real GDP at market prices of the base year $\bar{T}$. For the Finnish data that we use, $\bar{T}=2000$.

Figures 10-12 and Table 2 present the results of numerical experiments with the two alternative specifications of government spending. We include another numerical experiment in which we maintain tax rates constant at their average 1970-80 and all government revenues are transferred to the household. The presence of distortionary taxes requires us to recalibrate the household utility function parameters $\beta$ and $\gamma$. For the model with constant tax rates and all government revenue transferred, we calibrate $\beta=1.0040$ and $\gamma=0.4694$; for the model with taxes and all government revenue transferred, $\beta=1.0039$ and $\gamma=0.4707$; and, for the model with taxes and government consumption, $\beta=0.9979$ and $\gamma=0.4009$. Since the calibrated $\beta$ does not satisfy $\beta<1$ for the two models with all government revenue transferred, we set $\beta=0.9990$ in the numerical experiments with these models.

Notice that the contribution of TFP in the growth accounting differs between the model and the data because of the difference between the pro-

Figure 10. Model with government sector:

Detrended real GDP per working-age person

in Finland

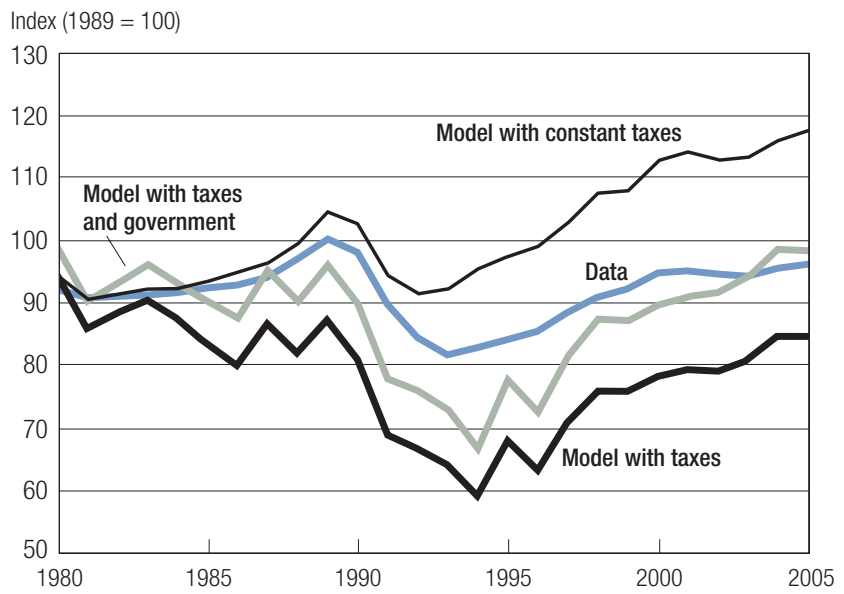


Figure 11. Model with government sector: Hours worked per working-age person in Finland

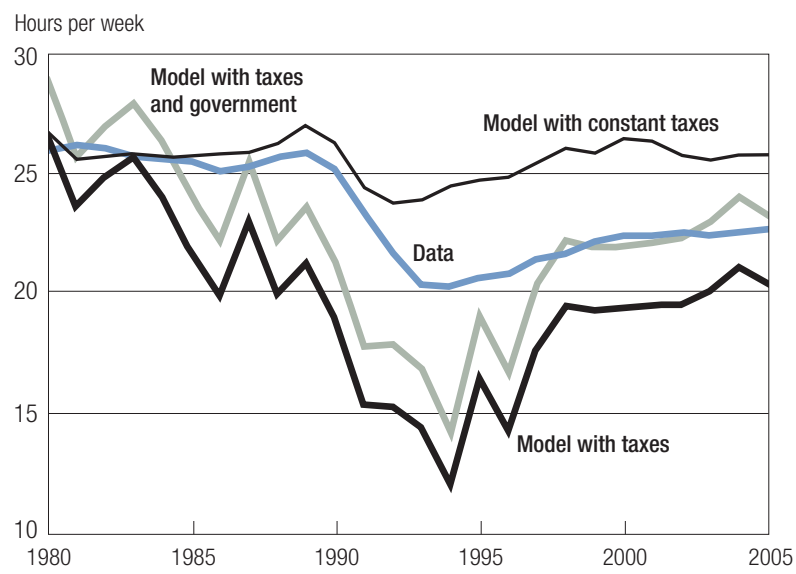

Figure 12. Model with government sector: Capital-labor ratio in Finland

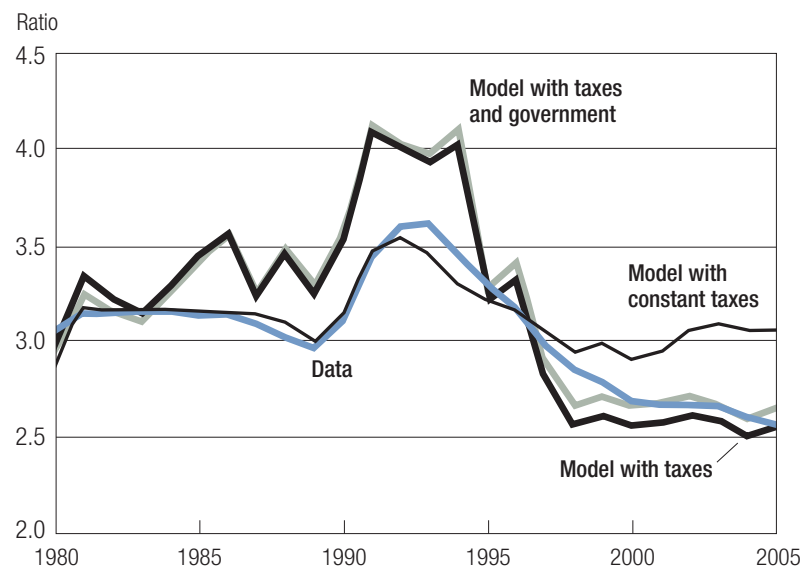

ductivity factor that we exogenously fix, $A_{t}$, and TFP, $\hat{A}_{t}$, which depends on endogenously determined consumption, $C_{t}$.

As we have seen under "Calibration and Results for the Base Case Model," the base case model does not account for the sharp fall in hours worked 1989-94. As Figure 11 shows, the introduction of distortionary taxes in our 
analysis helps in accounting for this feature of the data. If anything, the model overestimates the fall in hours worked. Conesa and Kehoe (2007) show that alternative utility functions with lower corresponding labor supply elasticities can produce a lower response of hours worked to changes in labor and consumption taxes in this sort of model. Ljunge and Ragan (2004) argue that the responses of labor supply to changes in taxes like those in Finland in the early 1990s - they focus on similar changes that occurred in Sweden at the same time - were large, but not as large as those predicted by our logarithmic utility function (1). Furthermore, Ragan (2005) and Rogerson (2007) argue that much of the revenues from taxes on labor in Scandinavia are used to finance subsidies and transfers to workers, which lower the effective tax rate on labor. This is a topic that deserves more research.

Figure 10 shows that the model with taxes also does a better job than the base case model in accounting for the continued fall through 1993 in detrended real GDP per working-age person in the data. Notice that the specification in which government consumption is wasted or enters the utility function separably significantly improves the performance of the model relative to the specification where tax revenues are lump-sum rebated. In this

Table 2. Government sector experiment for Finland: Decomposition of average annual changes in real output per working-age person (\%)

\begin{tabular}{lrrrr}
\hline & Data & $\begin{array}{c}\text { Model: } \\
\text { Constant } \\
\text { taxes }\end{array}$ & $\begin{array}{c}\text { Model: } \\
\text { Taxes }\end{array}$ & $\begin{array}{r}\text { Model: } \\
\text { Taxes and } \\
\text { government }\end{array}$ \\
\hline $\begin{array}{l}\text { Growth 1980-89 } \\
\text { change in Y/N }\end{array}$ & 2.92 & 3.12 & 1.09 & 1.80 \\
$\quad$ due to TFP & 3.13 & 2.95 & 3.23 & 3.23 \\
$\quad$ due to K/Y & -0.17 & 0.07 & 0.53 & 0.86 \\
$\quad$ due to L/N & -0.03 & 0.10 & -2.67 & -2.29 \\
& & & & \\
Crisis 1989-93 & & & & \\
change in Y/N & -3.14 & -1.16 & -5.75 & -4.93 \\
$\quad$ due to TFP & 0.05 & -0.09 & 1.30 & 0.86 \\
$\quad$ due to K/Y & 2.77 & 1.96 & 2.72 & 2.63 \\
$\quad$ due to $L / N$ & -5.96 & -3.03 & -9.77 & -8.42 \\
Recovery 1993-2005 & & & & \\
change in $Y / N$ & 3.33 & 4.00 & 4.32 & 4.48 \\
$\quad$ due to TFP & 4.04 & 3.93 & 3.40 & 3.69 \\
$\quad$ due to K/Y & -1.58 & -0.56 & -2.01 & -1.89 \\
$\quad$ due to $L / N$ & 0.87 & 0.64 & 2.93 & 2.69 \\
\hline
\end{tabular}


specification, increases in taxes generate negative income effects that induce households to provide more labor in the market than they would have done if the tax revenues were rebated.

Finally, notice that the model with constant taxes does not perform better than the base case model in accounting for the fall in hours or the length of the crisis. It is the evolution of distortionary taxes that improves these features of the model's performance, not their mere presence in the model. This is because we have calibrated the parameters $\beta$ and $\gamma$ so that the model is consistent with observed behavior over the period 1970-80. To induce households to supply as much work and to invest as much as they did during $1970-80$, we have to set $\beta$ and $\gamma$ to higher values when there are taxes than when there are no taxes.

\section{Two Sectors: Consumption and Investment}

We have defined investment in our growth accounting and base case model to be investment in current prices deflated by the GDP deflator. In this section, we develop an alternative model in which investment is investment in current prices deflated by the investment deflator. In this model, there is an intratemporal relative price that plays a major role, the relative price of investment to consumption. Figure 13 depicts the evolution of this relative price over the period 1980-2005. It is worth noting that some researchers argue that the national accounts do not fully capture the improvements in quality experienced by investment goods. (See, for example, Gordon 1990

\section{Figure 13. Relative price of investment to consumption in Finland}

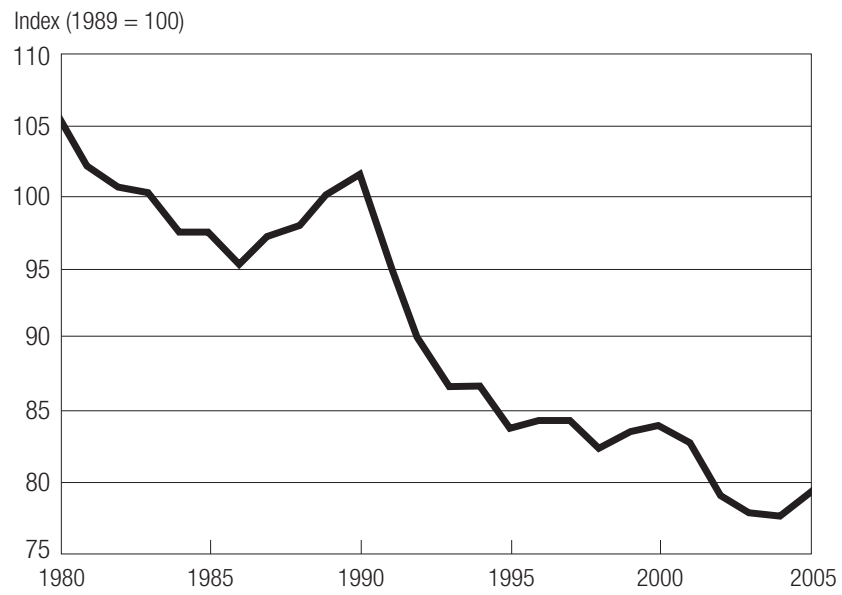


and, for a more recent contribution, Cummins and Violante 2002.)

We model the investment sector in the simplest possible way. Let $q_{t}$ be the relative price of investment goods to consumption goods. We assume that

$$
I_{t}=K_{t+1}-(1-\delta) K_{t}=\frac{X_{t}}{q_{t}}
$$

That is, there is a production technology that transforms $q_{t}$ units of consumption goods into one unit of the investment good. This specification is similar to that of Greenwood, Hercowitz, and Krusell (2000) and Rebelo (1991). The feasibility condition for the consumption good sector is

$$
C_{t}+X_{t}=A_{t} K_{t}^{\alpha} L_{t}^{1-\alpha}
$$

Combining (43) and (44), we obtain

$$
C_{t}+q_{t} I_{t}=A_{t} K_{t}^{\alpha} L_{t}^{1-\alpha}
$$

where

$$
I_{t}=K_{t+1}-(1-\delta) K_{t}
$$

and the budget constraint of the representative household becomes

$$
C_{t}+q_{t} I_{t}=w_{t} L_{t}+r_{t} K_{t}
$$

The first-order condition that characterizes households' consumption and savings behavior, (18), becomes

(48) $\frac{C_{t+1}}{C_{t}}=\frac{1}{q_{t}} \beta\left(\alpha A_{t+1} K_{t+1}^{\alpha-1} L_{t+1}^{1-\alpha}+(1-\delta) q_{t+1}\right)$.

The condition that characterizes households' labor and leisure behavior, (17), stays the same.

Definition. Given sequences of productivity, $A_{t}$, relative prices of the investment good, $q_{t}$, and working-age population, $N_{t}, t=T_{0}, T_{0}+1, \ldots$, and the initial capital stock, $\bar{K}_{T_{0}}$, an equilibrium with a consumption sector and an investment sector is sequences of wages, $w_{t}$, interest rates, $r_{t}$, consumption, $C_{t}$, labor, $L_{t}$, investment, $I_{t}$, and capital stocks, $K_{t}$, such that 
1. given the wages and interest rates, the representative household chooses consumption, labor, and capital to maximize the utility function (1) subject to the budget constraints (47), appropriate nonnegativity constraints, and the constraint on $\bar{K}_{T_{0}}$;

2. the wages and interest rates, together with the firms' choices of labor and capital, satisfy the cost minimization and zero profit conditions, (4) and (5); and

3. consumption, investment, labor, and capital satisfy the feasibility conditions (44), (45), and (46).

\section{Calibration and Results for the Two-Sector Model with Consumption and Investment}

The introduction of the investment sector, and the consequent introduction of the relative price of the investment good, requires that we make significant adjustments to the manner in which we match the model with the data. First, the numeraire is the consumption good. As a result, GDP in the data must be deflated by the consumption deflator, rather than the GDP deflator as in the one-sector environment. Second, we have to recompute a consistent measure of the capital stock using

$$
K_{t+1}=(1-\delta) K_{t}+\frac{X_{t}}{q_{t}}
$$

where $X_{t}$ is investment deflated by the consumption deflator. Since the relative price of investment changes every period, there is no method that is exactly equivalent to equations (8)-(10) for choosing the initial capital stock and the depreciation rate $\delta$. Some methods would take seriously the vintage nature of our capital stock and country-specific depreciation rules. Here we simply set

$$
\begin{aligned}
& \text { (50) } \frac{1}{26} \sum_{t=1980}^{2005} \frac{\delta q_{t} K_{t}}{\tilde{Y}_{t}}=0.1693 \\
& \text { (51) } \frac{q_{1960} K_{1960}}{\tilde{Y}_{1960}}=\frac{1}{10} \sum_{t=1961}^{1970} \frac{q_{t} K_{t}}{\tilde{Y}_{t}},
\end{aligned}
$$

where

$$
\tilde{Y}_{t}=C_{t}+q_{t} I_{t}
$$


is GDP in current prices deflated by the consumption good deflator. We calibrate $\delta=0.0629$.

As in the model with taxes, we have to modify our calculation of the exogenous productivity sequence,

$$
A_{t}=\frac{\tilde{Y}_{t}}{K_{t}^{1-\alpha} L_{t}^{\alpha}}
$$

Once again, however, we report TFP as conventionally measured, (41), in Table 3, where now

$$
\hat{Y}_{t}=C_{t}+q_{\bar{T}} I_{t}=C_{t}+I_{t}
$$

is real GDP at prices of the base year $\bar{T}$, where $q_{\bar{T}}=1$.

The change in the capital stock series changes the series for $r_{t}=\alpha Y_{t} / K_{t}$ in the first-order condition (18). Recalibrating $\beta$, we obtain $\beta=0.9708$. Since $w_{t}=(1-\alpha) Y_{t} / L_{t}$ in the first-order condition (17) remains the same, however, the calibration of $\gamma$ stays the same as in the base case model, $\gamma=0.2846$.

The results for the two-sector model discussed above are presented in the first two columns of Table 3 . The third column of Table 3 reports the results of a numerical experiment in which we introduce taxes and government consumption into the two-sector model. In this model, we calibrate $\beta=0.9790$ and $\gamma=0.4122$. The results for the base case model with two sectors in the second column of Table 3 are not very different from those for the base case model with one sector in the second column of Table 1. The two-sector model does a worse job of accounting for the depression, however, with output and hours worked falling even less than in the one-sector model. This is because the sharp fall in investment prices during the period 1990-93, seen in Figure 13, induces households in the two-sector model to invest more than in the one-sector model. The larger capital stock leads to higher wages and higher hours worked.

These general equilibrium effects are also present, but to a lesser extent, in the results for the two-sector model with taxes and government consumption presented in column 3 of Table 3 . In this case, however, the introduction of two sectors results in a modest improvement of the match of the model with the data over the results for the one-sector model with taxes and government consumption presented in the fourth column of Table 2. In the one-sector model with taxes and government consumption, hours worked fall too much during the crisis 1989-93 compared with the data. Overall, however, the introduction of two sectors into the model does not produce a substantial 
Table 3. Investment sector experiment for Finland: Decomposition of average annual changes in real output per working-age person (\%)

\begin{tabular}{|c|c|c|c|}
\hline & Data & $\begin{array}{c}\text { Model: } \\
\text { Base case }\end{array}$ & $\begin{array}{c}\text { Model: } \\
\text { Taxes and } \\
\text { government }\end{array}$ \\
\hline \multicolumn{4}{|c|}{ Growth 1980-89 } \\
\hline change in $Y / N$ & 2.92 & 2.97 & 0.77 \\
\hline due to TFP & 3.23 & 3.06 & 2.98 \\
\hline due to $K / Y$ & -0.27 & -0.53 & -0.26 \\
\hline due to $L / N$ & -0.03 & 0.44 & -1.96 \\
\hline \multicolumn{4}{|c|}{ Crisis 1989-93 } \\
\hline change in $Y / N$ & -3.14 & 0.22 & -3.01 \\
\hline due to TFP & 0.10 & -0.29 & -0.89 \\
\hline due to $K / Y$ & 2.72 & 0.65 & 0.57 \\
\hline due to $L / N$ & -5.96 & -0.14 & -2.69 \\
\hline \multicolumn{4}{|c|}{ Recovery 1993-2005 } \\
\hline change in $Y / N$ & 3.33 & 4.48 & 4.05 \\
\hline due to TFP & 3.74 & 3.83 & 3.56 \\
\hline due to $K / Y$ & -1.27 & 0.49 & -1.41 \\
\hline due to $L / N$ & 0.87 & 0.16 & 1.91 \\
\hline
\end{tabular}

improvement in the model's ability to account for Finnish macroeconomic performance during the crisis and recovery.

\section{Terms of Trade}

In this section, we open the model to foreign trade and subject it to termsof-trade shocks. As can be seen in Figure 14, the price of Finland's imports relative to its exports - the terms of trade -increased by almost 10 percent during the crisis period. Does this change in relative prices help us explain the evolution of GDP during this period? We modify the baseline model to incorporate trade with the rest of the world and to include three goods: a domestically produced good, an imported good, and a nontraded investment good. We model Finland as a small open economy. The price of Finnish imports, and thus the terms of trade, is exogenously given.

The representative household chooses consumption of the domestic good, consumption of the imported good, and leisure to maximize

$$
\sum_{t=T_{0}}^{\infty} \beta^{t}\left(\gamma \log \left(v\left(C_{d, t}, C_{m, t}\right)\right)+(1-\gamma) \log \left(\bar{h} N_{t}-L_{t}\right)\right)
$$




\section{Figure 14. Relative prices in Finland}

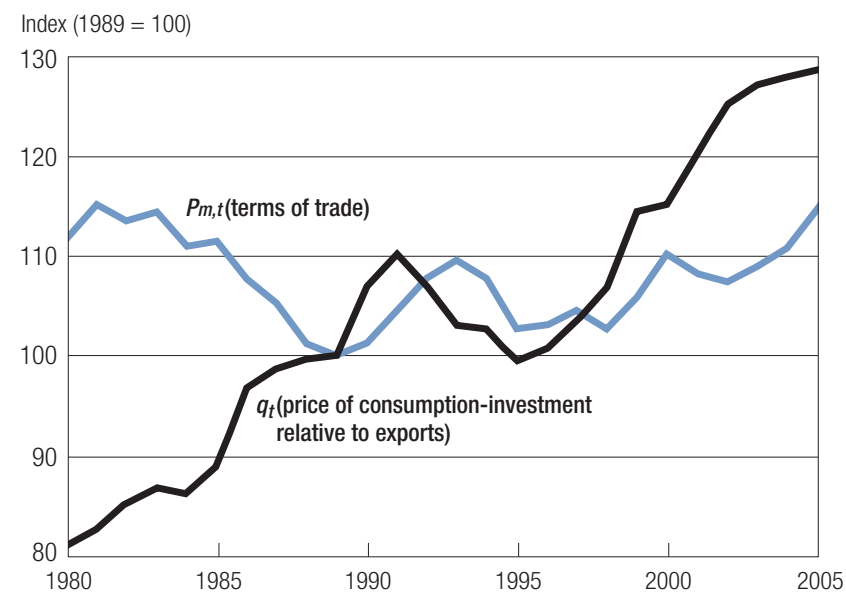

subject to the sequence of budget constraints

$$
p_{d, t} C_{d, t}+p_{m, t} C_{m, t}+q_{t}\left(K_{t+1}-(1-\delta) K_{t}\right)=w_{t} L_{t}+r_{t} K_{t}
$$

appropriate nonnegativity constraints, and a constraint on the initial stock of capital, $\bar{K}_{T_{0}}$. In what follows, we choose the domestic good as numeraire, setting $p_{d, t}=1$. The price of the investment good, relative to the domestically produced good, is $q_{t}$. The relative price of the imported good is $p_{m, t}$. Since we assume that the export good is the same as the domestic good, $p_{m, t}$ is also the terms of trade.

The production of the domestic good, (3), and the corresponding profit maximization conditions are the same as in the base case model, (4) and (5). The investment good is made by combining the domestic good and the imported good using a constant elasticity of substitution production function, which is usually referred to as the Armington aggregator,

$$
I_{t}=K_{t+1}-(1-\delta) K_{t}=D_{t}\left(\omega I_{d, t}^{\rho}+(1-\omega) I_{m, t}^{\rho}\right)^{\frac{1}{\rho}}
$$

where $I_{d, t}$ and $I_{m, t}$ are, respectively, the use of domestic goods and imports in the production of the investment good. The elasticity of substitution between imports and domestic goods in the production of the investment good, the Armington elasticity, is $\sigma=1 /(1-\rho)$. The parameter $\omega$ governs the proportion in which domestic and imported goods are used in produc- 
tion. The parameter $D_{t}$ determines the amounts of imports and domestically produced goods needed to produce one unit of the investment good. $D_{t}$ evolves over time to account for the relative price of the investment good relative to exports.

The problem of firms that produce the investment good is choose $I_{d, t}$ and $I_{m, t}$ to solve

(58) $\min I_{d, t}+p_{m, t} I_{m, t}$

$$
\text { s.t. } \bar{I}_{t} \leq D_{t}\left(\omega I_{d, t}^{\rho}+(1-\omega) I_{m, t}^{\rho}\right)^{\frac{1}{\rho}} \text {, }
$$

where $\bar{I}_{t}$ is some target production level.

Solving this minimization problem, together with the zero profit condition

$$
q_{t} D_{t}\left(\omega I_{d, t}^{\rho}+(1-\omega) I_{m, t}^{\rho}\right)^{\frac{1}{\rho}}=I_{d, t}+p_{m, t} I_{m, t}
$$

results in the following first-order conditions:

(60) $1=q_{t} \omega I_{d, t}^{\rho-1} D_{t}\left(\omega I_{d, t}^{\rho}+(1-\omega) I_{m, t}^{\rho}\right)^{\frac{1-\rho}{\rho}}$

(61) $p_{m, t}=q_{t}(1-\omega) I_{m, t}^{\rho-1} D_{t}\left(\omega I_{d, t}^{\rho}+(1-\omega) I_{m, t}^{\rho}\right)^{\frac{1-\rho}{\rho}}$.

The feasibility constraints for the domestic good and the imported good are

(62) $C_{d, t}+I_{d, t}+X_{t}=A_{t} K_{t}^{\alpha} L_{t}^{1-\alpha}$

(63) $C_{m, t}+I_{m, t}=M_{t}$,

where $M_{t}$ is imports and $X_{t}$ is exports. The trade balance condition is (64) $X_{t}=p_{m, t} M_{t}$.

We later experiment with an alternative specification in which the trade balance is specified exogenously. 
In choosing a functional form for the household's utility over imports and domestic goods, $v\left(C_{d}, C_{m}\right)$, we assume that the household's preferences over the two goods identical to the production technology for producing the investment good,

$$
v\left(C_{d, t}, C_{m, t}\right)=D_{t}\left(\omega C_{d, t}^{\rho}+(1-\omega) C_{m, t}^{\rho}\right)^{\frac{1}{\rho}}
$$

This assumption is commonly used, not because it is justified by data on the use of imports, but because it simplifies analysis of the model. It would be worth investigating if modifying this assumption has significant effects on the quantitative models of trade in which it is employed.

Defining

$$
C_{t}=D_{t}\left(\omega C_{d, t}^{\rho}+(1-\omega) C_{m, t}^{\rho}\right)^{\frac{1}{\rho}}
$$

we can rewrite the household's problem as one of maximizing the utility function (1) subject to the sequence of budget constraints

$$
q_{t}\left(C_{t}+K_{t+1}-(1-\delta) K_{t}\right)=w_{t} L_{t}+r_{t} K_{t}
$$

appropriate nonnegativity constraints, and a constraint on the initial stock of capital, $\bar{K}_{T_{0}}$. Notice that this formulation of the household's problem closely resembles the one in the base case model. Our assumption about household preferences in (65) implies that households demand imports and domestic goods in the same proportions as investment good firms. This feature is very convenient since now, adding up condition (66) and (57), we obtain

$$
C_{t}+K_{t+1}-(1-\delta) K_{t}=D_{t}\left(\omega Z_{t}^{\rho}+(1-\omega) M_{t}^{\rho}\right)^{\frac{1}{\rho}}
$$

We can also rewrite (62) as

$$
Z_{t}+X_{t}=A_{t} K_{t}^{\alpha} L_{t}^{1-\alpha}
$$

Conditions (68) and (69) are the new feasibility conditions. Rather than have consumption good producing firms and investment good producing firms, we can model a single type of firm that uses all of the imports, $M_{t}$, and all of the domestically produced good that is not exported, $Z_{t}$, to produce a 
consumption-investment aggregate. Solving the problem of this single type of firm generates first-order conditions very similar to (60) and (61):

(70) $1=q_{t} \omega Z_{t}^{\rho-1} D_{t}\left(\omega Z_{t}^{\rho}+(1-\omega) M_{t}^{\rho}\right)^{\frac{1-\rho}{\rho}}$

$$
p_{m, t}=q_{t}(1-\omega) M_{t}^{\rho-1} D_{t}\left(\omega Z_{t}^{\rho}+M_{t}^{\rho}\right)^{\frac{1-\rho}{\rho}} .
$$

Definition. Given sequences of productivity, $A_{t}$, the terms of trade, $p_{m, t}$, shocks to the investment-consumption good production function, $D_{t}$, working-age population, $N_{t}, t=T_{0}, T_{0}+1, \ldots$, and the initial capital stock, $\bar{K}_{T_{0}}$, an equilibrium with trade and terms-of-trade shocks is sequences of wages, $w_{t}$, interest rates, $r_{t}$, consumption-investment prices, $q_{t}$, consumption, $C_{t}$, labor, $L_{t}$, capital, $K_{t}$, output, $Y_{t}$, imports, $M_{t}$, exports, $X_{t}$, and domestic goods used in production, $Z_{t}$, such that

1. given wages, interest rates, and prices, the representative household's choices over consumption, labor, and capital solve the problem of maximizing the utility function (55) subject to the budget constraint (67), appropriate nonnegativity constraints, and the constraint on initial capital $\bar{K}_{T_{0}}$;

2. the wages and interest rates, together with the domestic good producing firms' choices of labor and capital, satisfy the cost minimization and zero profit conditions, (4) and (5);

3. the terms of trade and the price of the consumption-investment good, together with the consumption-investment good firm's choices of imports and inputs of the domestic good, satisfy the cost minimization and zero profit conditions, (70) and (71);

4. consumption, labor, capital, inputs of the domestic good, imports, and exports satisfy the feasibility conditions (68) and (69);

5. trade is balanced, (64).

We characterize the equilibrium of this model as we have in the previous sections, with some slight modifications. First, given the terms of trade, we can solve a static problem that determines the demand for domestic goods and imports and most importantly, the price of the investment and consumption goods. Second, we can incorporate this information into the household's optimality conditions.

The first-order conditions from (70) and (71) can be combined to yield 
(72) $Z_{t}=\left(\frac{\omega p_{m, t}}{1-\omega}\right)^{\frac{1}{1-\rho}} M_{t}$.

Substituting (72) into the profit function, and using the fact that profits must be zero, we can solve for the price of the consumption-investment good,

$$
q_{t}=D_{t}^{-1}\left(\omega^{\frac{1}{1-\rho}}+(1-\omega)^{\frac{1}{1-\rho}} p_{m, t}^{\frac{-\rho}{1-\rho}}\right)^{\frac{1-\rho}{-\rho}}
$$

Solving (64) and (69) for $Z_{t}$ and substituting it into (72) yields the demand function for imports and domestic goods used in production,

$$
\begin{aligned}
& M_{t}=(1-\omega)^{\frac{1}{1-\rho}} A_{t} K_{t}^{\alpha} L_{t}^{1-\alpha} p_{m, t}^{\frac{1}{\rho-1}}\left(q_{t} D_{t}\right)^{\frac{\rho}{1-\rho}} \\
& Z_{t}=\omega^{\frac{1}{1-\rho}} A_{t} K_{t}^{\alpha} L_{t}^{1-\alpha}\left(q_{t} D_{t}\right)^{\frac{\rho}{1-\rho}}
\end{aligned}
$$

Combining the household's optimality conditions with factor pricing equations from (4) and (5) yields a system of equations that is very similar to those in the base case model, (21) and (22),

$$
\frac{(1-\alpha) A_{t} K_{t}^{\alpha} L_{t}^{-\alpha}}{q_{t}}\left(\bar{h} N_{t}-L_{t}\right)=\frac{1-\gamma}{\gamma} C_{t}, \quad t=T_{0}, T_{0}+1, \ldots, T_{1}
$$

$$
\frac{C_{t+1}}{C_{t}}=\beta\left(1-\delta+\frac{\alpha A_{t+1} K_{t+1}^{\alpha-1} L_{t+1}^{\alpha}}{q_{t+1}}\right), t=T_{0}, T_{0}+1, \ldots, T_{1}-1
$$

As in the base case model, we use the feasibility constraint to solve out $C_{t}$ in (76) and (77). We use (74) and (72) to substitute out for $M_{t}$ and $Z_{t}$. Setting $K_{T_{1}+1}=g n K_{T_{1}}$, we again have a system of $2\left(T_{1}-T_{0}\right)-1$ nonlinear equations in $2\left(T_{1}-T_{0}\right)-1$ unknowns.

\section{Calibration and Results for the Model with Terms-of-Trade Shocks}

The calibration of the initial capital stock and the depreciation rate are done in a similar way as in the "Terms of Trade" section. We choose $\delta$ and $K_{1960}$ so that the following conditions are satisfied: 
(78) $\frac{1}{26} \sum_{t=1980}^{2005} \frac{\delta q_{t} K_{t}}{q_{t}\left(C_{t}+I_{t}\right)}=\frac{1}{26} \sum_{t=1980}^{2005} \frac{\delta K_{t}}{C_{t}+I_{t}}=0.1693$

(79) $\frac{K_{1960}}{C_{1960}+I_{1960}}=\frac{1}{10} \sum_{t=1961}^{1970} \frac{K_{t}}{C_{t}+I_{t}}$.

We calibrate $\delta=0.0583$.

In the first version of our open economy model, we assume that trade is balanced every period. We set

(80) $\tilde{C}_{t}=\tilde{Y}_{t}-\tilde{I}_{t}$

define the current value of consumption, subsuming the trade balance into consumption, and set

(81) $\tilde{X}_{t}=\tilde{M}_{t}$,

letting the current value of exports be equal to the current value of imports in the data.

The investment-consumption good production function adds two new production function parameters, $\omega$ and $\rho$, and two new sequences of exogenous parameters, $D_{t}$ and $p_{m, t}$. The parameter $\rho$ is typically not calibrated but is chosen based on empirical estimates of the elasticity of substitution between domestic goods and imports. There is considerable debate over the value of this parameter (see, for example, Ruhl 2004), but a common value is $\rho=0.5$, corresponding to an Armington elasticity $\sigma=2$. We can rewrite (72) as

$$
\frac{\omega}{1-\omega}=\left(\frac{Z_{t}}{p_{m, t} M_{t}}\right)^{1-\rho} p_{m, t}^{-\rho}
$$

and use data on the terms of trade, output, imports, and exports to calibrate $\omega$. We use (82) to calculate $\omega$ over 1980-2005 and take the average; $\omega=$ 0.6219 . With this value for $\omega$, we can compute

$$
D_{t} q_{t}=\left(\omega^{\frac{1}{1-\rho}}+(1-\omega)^{\frac{1}{1-\rho}} p_{m, t}^{\frac{-\rho}{1-\rho}}\right)^{\frac{1-\rho}{-\rho}}
$$


and use this to find values for $D_{t}$. From the data we compute the deflator for consumption plus investment and divide it through by the deflator for exports to produce $q_{t}$. Dividing the expression for $D_{t} q_{t}$ in (83) by $q_{t}$ yields the series $D_{t}$.

We next turn to the construction of the capital stock, the depreciation rate $\delta$, and the productivity parameters $A_{t}$. We start by deflating the components of GDP in current prices by the export price deflator. Deflating current GDP produces

$$
\frac{\tilde{Y}_{t}-\tilde{X}_{t}+\tilde{M}_{t}}{p_{x, t}}=q_{t}\left(C_{t}+I_{t}\right)
$$

deflating exports produces

(85) $\frac{\tilde{X}_{t}}{p_{x, t}}=X_{t}$;

and deflating imports produces

(86) $\frac{\tilde{M}_{t}}{p_{x, t}}=p_{m, t} M_{t}$.

Using the first-order conditions for the households' problem, (76) and (77), we calibrate $\beta=0.9472$ and $\gamma=0.2825$.

Using the terms of trade $p_{m, t}$ and the price of consumption-investment $q_{t}$, we recover the quantities $C_{t}+I_{t}, X_{t}$, and $M_{t}$. To relate the quantities from the national accounts to the productivity parameter $A_{t}$, we substitute (62) into (68),

$$
C_{t}+I_{t}=D_{t}\left(\omega\left(A_{t} K_{t}^{\alpha} L_{t}^{1-\alpha}-X_{t}\right)^{\rho}+(1-\omega) M_{t}^{\rho}\right)^{\frac{1}{\rho}}
$$

and solve to obtain

$$
A_{t}=\frac{\omega^{-\frac{1}{\rho}}\left(\left(C_{t}+I_{t}\right)^{\rho} D_{t}^{-\rho}-(1-\omega) M_{t}^{\rho}\right)^{\frac{1}{\rho}}+X_{t}}{K_{t}^{\alpha} L_{t}^{1-\alpha}}
$$

Notice that $A_{t}$ is no longer a simple function of real GDP, capital, and 
labor. In the growth accounting reported in Table 4, we calculate TFP using the conventional measure, (41), where

$$
\hat{Y}_{t}=q_{\bar{T}}\left(C_{t}+I_{t}\right)+X_{t}-p_{m, \bar{T}} M_{t}=\left(C_{t}+I_{t}\right)+X_{t}-M_{t}
$$

is real GDP at prices in the base year $\bar{T}$. Notice that, even though the trade balance in current prices is always zero, the real trade balance is only zero when the terms of trade are equal to those in the base period.

The results from our open economy model are presented in the second column of Table 4. The model does a reasonable job of accounting for the periods before and after the crisis, but capital and labor vary too much in the early period and not enough in the later period. During the crisis period, the model performs a little better than the base case model, with output falling by about half as much as in the data. As in the base case model, the capitaloutput ratio grows and hours worked falls, but not by as much as in the data. The model does most poorly in generating a large enough response in hours worked. The decrease in the model is only 45 percent of that in the data. We conclude that including the terms-of-trade reversal that Finland suffered

Table 4. Foreign sector experiment for Finland: Decomposition of average annual changes in real output per working-age person (\%)

\begin{tabular}{lrrr}
\hline & & $\begin{array}{c}\text { Model: } \\
\text { Base case }\end{array}$ & $\begin{array}{c}\text { Model: } \\
\text { Exogenous } \\
\text { trade balance }\end{array}$ \\
\hline $\begin{array}{l}\text { Growth 1980-89 } \\
\text { change in } Y / N\end{array}$ & 2.92 & 2.40 & 2.37 \\
$\quad$ due to TFP & 2.96 & 2.54 & 2.82 \\
$\quad$ due to $K / Y$ & -0.01 & -1.31 & -1.22 \\
$\quad$ due to $L / N$ & -0.03 & 1.16 & 0.78 \\
& & & \\
Crisis 1989-93 & & & \\
change in $Y / N$ & -3.14 & -1.55 & -0.32 \\
$\quad$ due to TFP & -0.16 & -0.19 & -0.62 \\
$\quad$ due to $K / Y$ & 2.98 & 1.28 & 1.80 \\
$\quad$ due to $L / N$ & -5.96 & -2.64 & -1.49 \\
& & & \\
$\begin{array}{l}\text { Recovery } 1993-2005 \\
\text { change in } Y / N\end{array}$ & & & \\
$\quad$ due to TFP & 3.33 & 4.44 & 4.34 \\
$\quad$ due to $K / Y$ & 4.06 & 4.87 & 5.10 \\
$\quad$ due to $L / N$ & -1.59 & -0.83 & -1.01 \\
\hline
\end{tabular}


during the depression does not significantly improve the model.

In the model with terms-of-trade shocks, we have assumed that trade is balanced every period. In the data, however, Finland ran a small positive trade balance prior to the crisis and a large positive trade balance following the crisis. In 1998, net exports peaked at almost 11 percent of current GDP. We incorporate the trade balance into this framework in a very simple way. We assume that the real trade balance is exogenously given and perfectly foreseen. Denoting real net exports as $B_{t}$, we rewrite the feasibility constraint, (69), as

$$
Z_{t}+X_{t}+B_{t}=A_{t} K_{t}^{\alpha} L_{t}^{1-\alpha}
$$

so that when the trade balance is positive, there is less output to devote to producing consumption and investment goods. The model is calibrated and computed in the same way as before, with the addition of an extra exogenous variable, real net exports. It is possible to model the real net trade balance as corresponding to exogenously fixed net lending abroad in the household's budget constraint. Here it is just a net use of domestic resources. In the model with the exogenous trade balance, the calibration of the parameters becomes $\omega=0.6143, \beta=0.9486$, and $\gamma=0.2813$.

The results from this model are presented in the third column of Table 4. The results of this model are very similar to those of the model with balanced trade except during the crisis period. During the crisis, net exports are growing, driving down income left over for households. In our model, as in that of Chari, Kehoe, and McGrattan (2005), this induces households to supply more labor than they would have done otherwise, which leads to GDP falling less than it would have done otherwise. This effect is visible in Table 4, where the decline in hours worked during the crisis in the model with the exogenous trade balance is only 54 percent as large as it is in the model with balanced trade. As Chakraborty (2006) has argued, this impact depends crucially on the specification of the utility function. With a utility function of the sort used by Correia, Neves, and Rebelo (1995), for example,

$$
\sum_{t=T_{0}}^{\infty} \beta^{t} \log \left(\gamma C_{t}-\frac{g^{t} L_{t}^{v}}{v}\right)
$$

in which consumption enters in a quasi-linear manner, this income effect disappears, and hours worked fall roughly as much in the specification with the exogenous trade balance as they do in the specification with balanced trade. 


\section{Chain-Weighted Quantity Indexes}

Currently, the U.S. Bureau of Economic Analysis in its National Income and Product Accounts (NIPA) and the U.N. Statistics Division in its System of National Accounts (SNA) recommend the use of chain-weighted price indexes to deflate GDP. In this section we explain how the analysis of the model with taxes, the model with investment, and the model with trade would be altered if the underlying data were chain weighted. In 2006, Finland changed the real variables in its national income accounts to Laspeyres chain-weighted quantity indexes. It provides chain-weighted quantity indexes starting in 2000. Real variables for 1975-2000 are measured in prices of the base year 2000 , and those for earlier years are measured in prices of the earlier based years spliced with the data of the base year 2000 .

Before discussing chain weighting, it is worth making a couple of points. First, the distinction between chain-weighted data and data in base period prices is only relevant in the analysis of a model in which there is some component of GDP whose relative price can vary with respect to the other components. This is not the case in the base case model. It is the case, however, in the three other models analyzed in this paper. In the model with taxes, the price of consumption relative to investment is $1+\tau_{t}^{c}$; in the model with investment, the price of investment relative to consumption is $q_{t}$; and, in the model with trade, the price of consumption-investment relative to exports is $q_{t}$ while the price of imports relative to exports is $p_{m, t}$. Second, there are different methodologies for chain weighting. The United States' NIPA accounting uses Fisher chain weights. So does Statistics Canada. Most countries that follow U.N. SNA national income accounting currently use Laspeyres chain weighting, although both Fisher weighting and Paasche weighting are allowed. When the United States switched to chain weighting, it recalculated real GDP and its components, going back to 1929, as chain-weighted quantity indexes. In contrast, when Finland switched to chain weighting, it spliced the chain-weighted data that started in 2000 with earlier data measured in base period prices.

We discuss the decomposition of real GDP into its components that is relevant for the model with investment when the data use Laspeyres chain weighting. Recall that in that model, we choose consumption to be the numeraire, where consumption corresponds to all components of GDP that are not included in investment. Here is our problem: We are given data on real GDP and real investment, $\hat{Y}_{t}$ and $\hat{I}_{t}$, GDP and investment in current prices, $\tilde{Y}_{t}$ and $\tilde{I}_{t}$. We know that $\tilde{C}_{t}=\tilde{Y}_{t}-\tilde{I}_{t}$ is consumption in current prices. We want to calculate real consumption $\hat{C}_{t}$. With real data measured in base period prices, there is no problem in calculating 
(92) $\hat{C}_{t}=\hat{Y}_{t}-\hat{I}_{t}$.

The price deflator for consumption is then simply found as

(93) $p_{c, t}=\frac{\tilde{C}_{t}}{\hat{C}_{t}}$.

With chain-weighted variables, a problem arises because the decomposition of real GDP into its components is not additive. That is, equation (92) does not hold. Instead,

(94) $\hat{Y}_{t}=\frac{p_{c, t} \hat{C}_{t}+q_{t} \hat{I}_{t}}{p_{y, t}}$,

where

$$
p_{y, t}=\frac{p_{c, t} \hat{C}_{t}+q_{t} \hat{I}_{t}}{p_{c, t-1} \hat{C}_{t}+q_{t-1} \hat{I}_{t}}
$$

which implies that

(96) $\hat{Y}_{t}=\frac{p_{c, t-1} \hat{C}_{t}+q_{t-1} \hat{I}_{t}}{p_{c, t-1} \hat{C}_{t-1}+q_{t-1} \hat{I}_{t-1}} \hat{Y}_{t-1}$,

where $\hat{Y}_{\bar{T}}=\tilde{Y}_{\bar{T}}$ is the reference year. When working with data in base year prices, the term base year identifies the year whose relative prices are used in each period of the data series, that is, the fixed prices. In chain-weighted data, the base period is always changing. In equation (96), the prices from the previous period are used to weight the current period's quantities, which is why this procedure is referred to as Laspeyres chain weighting. We rewrite (96) as

(97) $\hat{Y}_{t}=\frac{\frac{\tilde{C}_{t-1}}{\hat{C}_{t-1}} \hat{C}_{t}+\frac{\tilde{I}_{t-1}}{\hat{I}_{t-1}} \hat{I}_{t}}{\tilde{Y}_{t-1}} \hat{Y}_{t-1}$

and calculate 


$$
\hat{C}_{t}=\frac{\hat{C}_{t-1}}{\tilde{C}_{t-1}}\left(\frac{\tilde{Y}_{t-1}}{\hat{Y}_{t-1}} \hat{Y}-\frac{\tilde{I}_{t-1}}{\hat{I}_{t-1}} \hat{I}_{t}\right)
$$

which is a first-order difference equation that we can use to calculate a series for $\hat{C}_{t}$ to use in the model. The initial condition is $\hat{C}_{\bar{T}}=\tilde{C}_{\bar{T}}$, where $\bar{T}$ is the reference year used by the statistical agency in computing the real data, which for Finland is 2000.

After performing numerical experiments with the model, we can transform our results into a chain-weighted quantity index for GDP using the analogue of (96),

$$
\hat{Y}_{t}=\frac{C_{t}+q_{t-1} I_{t}}{C_{t-1}+q_{t-1} I_{t-1}} \hat{Y}_{t-1}
$$

where $\hat{Y}_{\bar{T}}=C_{\bar{T}}+I_{\bar{T}}$.

Working with Fisher chain weights is slightly more complicated, but the same ideas apply. Real GDP is still computed using (94), but the GDP deflator, $p_{y, t}$, is now of the form

$$
p_{y, t}=\left(\frac{p_{c, t} \hat{C}_{t-1}+q_{t} \hat{I}_{t-1}}{p_{c, t-1} \hat{C}_{t-1}+q_{t-1} \hat{I}_{t-1}}\right)^{\frac{1}{2}}\left(\frac{p_{c, t} \hat{C}_{t}+q_{t} \hat{I}_{t}}{p_{c, t-1} \hat{C}_{t}+q_{t-1} \hat{I}_{t}}\right)^{\frac{1}{2}}
$$

which is the geometric average of a Laspeyres price index and a Paasche price index. An advantage of using a Fisher price index is that the quantity index is also of the Fisher form

$$
\hat{Y}_{t}=\left(\frac{p_{c, t-1} \hat{C}_{t}+q_{t-1} \hat{I}_{t}}{p_{c, t-1} \hat{C}_{t-1}+q_{t-1} \hat{I}_{t-1}}\right)^{\frac{1}{2}}\left(\frac{p_{c, t} \hat{C}_{t}+q_{t} \hat{I}_{t}}{p_{c, t} \hat{C}_{t-1}+q_{t} \hat{I}_{t-1}}\right)^{\frac{1}{2}} \hat{Y}_{t-1}
$$

After substituting out the consumption prices, we have

$$
\text { (102) } \frac{\tilde{C}_{t-1}}{\hat{C}_{t-1}} \hat{C}_{t}^{2}+\hat{C}_{t}\left(q_{t-1} \hat{I}_{t}-\frac{\hat{Y}_{t}^{2}}{\tilde{Y}_{t}} \frac{\tilde{Y}_{t-1}}{\hat{Y}_{t-1}^{2}} q_{t} \hat{I}_{t-1}\right)-\frac{\hat{Y}_{t}^{2}}{\tilde{Y}_{t}} \frac{\tilde{Y}_{t-1}}{\hat{Y}_{t-1}^{2}} \tilde{C}_{t} \hat{C}_{t-1}=0
$$


which is a quadratic first-order difference equation in $\hat{C}_{t}$, where again the initial condition is $\hat{C}_{\bar{T}}=\tilde{C}_{\bar{T}}$.

As we have explained, the data on real GDP and its components in Finland for the period 2000-2005 are Laspeyres chain-weighted quantity indexes. This implies that the data for 2002-5 differ from real data measured in prices of the base year 2000: the reference year for the chain-weighted data is the same as the base year for the fixed base year data, 2000. Furthermore, for Laspeyres chain-weighted data constructed as in (96), the data for the year after the reference year are the same as the real data measured in prices of the reference year. We have redone the numerical experiments for the model with taxes, the two-sector model with consumption and investment, and the model with terms-of-trade shocks, taking into account that the data for Finland 2002-5 is chain-weighted data, using equations like (98) to disaggregate real GDP into the components relevant for the model and using equations like (96) to construct real GDP in the results of our numerical experiments. These recalculations have no noticeable impact on our results because so little of our data is chain-weighted. As we move further from the reference year, however, chain-weighted data can look very different from real data measured in prices of a fixed base year. Redoing the analysis of the Great Depression of the 1930s in the United States using the Fisher chain-weighted data with reference year 2000 now published by the U.S. Bureau of Economic Analysis, for example, would produce significant differences from an analysis that uses real data with fixed base year price weights.

\section{Endogenous Productivity}

In each of the three variants of the model that we have studied - the model with taxes and government consumption, the model with a consumption sector and an investment sector, and the open economy model with terms-oftrade shocks - the exogenous productivity sequence that enters into the model differs from conventionally measured TFP. In this section, we ask whether any of these variants of our model help explain the TFP drop in 1989-92.

Figure 15 compares the sequence for TFP in the base case model, (12), with the productivity sequences for each of the three variants of the model: (40) for the model with taxes and government, (53) for the model with consumption and investment, and (88) for the model with terms-of-trade shocks. In Figure 15 , each productivity sequence is reported as $A_{t}^{1 /(1-\alpha)}$ detrended by a growth rate of 2 percent per year. One view of what a successful model of endogenous TFP would be that it should generate a horizontal line for this series. Of course, even that would leave the 2 percent growth trend unexplained.

Notice how poorly the three variants of the model fare as theories of TFP during the crisis. In each of these models, the exogenous productivity falls 


\section{Figure 15. Detrended exogenous productivity} in variants of the Finland model

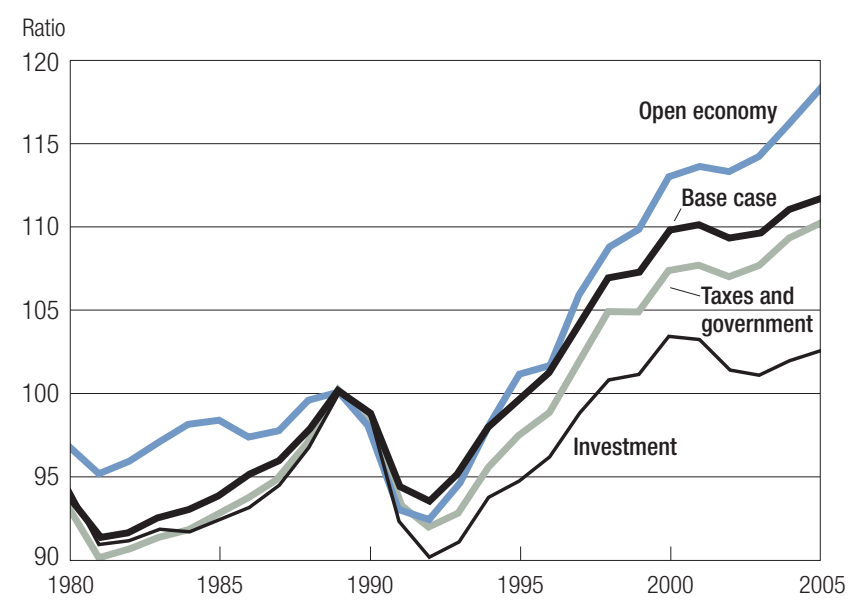

even more than TFP. This probably comes as no surprise for the model with taxes and government consumption because we do not expect GDP at factor prices to have a systematic countercyclical relation with GDP at market prices. It also comes as no surprise for the model with consumption and investment because Figure 13 indicates that the relative price of investment fell sharply during the depression, making it even more difficult to explain the drop in TFP. Perhaps, it is surprising to some that the model with the terms-of-trade shocks does so poorly. As Kehoe and Ruhl (2007) explain, however, adverse terms-of-trade shocks do not translate into TFP shocks because conventional national income accounting strips them out of measures of real GDP.

To say that the models do poorly in explaining the TFP drop during the depression is not to say that they do poorly everywhere. Figure 15 indicates that much of the spectacular growth in Finland over the period 1993-2005 is due to declines in the relative price of investment. Nonetheless, the major question left open by our analysis is, Why did TFP fall so sharply in 1989-92?

\section{Conclusions}

Our analysis of the 1989-93 depression in Finland is an example of how the application of a methodology can guide research. A good methodology provides discipline to the researcher; in the depressions methodology developed by Cole-Ohanian and Kehoe-Prescott, this discipline is provided by growth accounting. The candidate explanation not only must replicate the behavior 
of GDP, but also must manifest itself in the behavior of investment, labor, and total factor productivity. The numerical experiments with the base case model presented under "Calibration and Results for the Base Case Model" indicate that the depression in Finland is only partially accounted for by TFP, with the remainder due to a decrease in hours worked. Considering different variants of the base case model, we find that incorporating the observed changes in tax policies substantially improves the model's ability to replicate the data.

We have devoted a large fraction of our analysis - much more than that found in a typical journal article - to a discussion of the mapping between models and data. The key aspect of quantitative theory, such as the depressions methodology, is the careful comparison of models and data. To make these comparisons meaningful, we have used our models to determine how to measure variables, such as productivity, from the data, and we have used national accounting definitions to determine how to construct variables, such as GDP, from the models in ways that are comparable to the data. Although our exposition of the four models above may be useful in other circumstances, the map between a model and data is intrinsically model specific.

\section{Appendix A: Computational Algorithm}

This section describes the MATLAB programs "depressions.m" and "solveModel. $\mathrm{m}$ " that solve for the model's equilibrium by finding the solution to the system of equations derived under "Computation of Equilibrium." These programs, the necessary input files, and the calibration data can be found at www.greatdepressionsbook. com.

\section{Program Inputs}

The user must provide two files to the program. The first file should be named "param. txt" and consist of a single column vector of the parameters $\beta, \gamma, \delta, \alpha, g$, and $K_{T_{0}}$. The second file should be named "data.txt" and contain a $\left(T_{1}-T_{0}\right) \times 6$ matrix of values: levels of TFP, $A_{t}$, working-age population (in thousands), $N_{t}$, available hours, $N_{t} \bar{h}$, consumption tax rates, labor tax rates, and capital tax rates. These files must be in a form that can be interpreted by MATLAB. One method is to enter the data into a Microsoft Excel spreadsheet and save the file as a tab delimited file.

\section{Program Output}

Upon successful completion, the program will save a $\left(T_{1}-T_{0}\right) \times 6$ matrix of values to the file "output.xls," which is a tab delimited file. This file can be opened in Excel for inspection or to create plots. The data can also be directly manipulated in MATLAB. The variables in the file are $Y_{t} / N_{t}, X_{t} / Y_{t}, L_{t} /\left(\bar{h} N_{t}\right), C_{t} / Y_{t}, K_{t} / Y_{t}$, and $r_{t}-\delta$. 


\section{Solution Method}

Choosing $K_{T_{0}+1}, K_{T_{0}+2}, \ldots, K_{T_{1}}$ and $L_{T_{0}}, L_{T_{0}+1}, \ldots, L_{T_{1}}$ to satisfy (25) for $t=T_{0}$, $T_{0}+1, \ldots, T_{1}$, and (26) for $t=T_{0}, T_{0}+1, \ldots, T_{1}-1$, requires solving $2\left(T_{1}-T_{0}\right)-1$ equations in $2\left(T_{1}-T_{0}\right)-1$ unknowns. The accompanying MATLAB program uses Newton's method to solve the system of equations. Define the stacked vector of variables $x=\left[K_{T_{0}+1}, K_{T_{0}+2}, \ldots, K_{T_{1}}, L_{T_{0}}, L_{T_{0}+1}, \ldots, L_{T_{1}}\right]^{\prime}$ and arrange the system of equations so that they are of the form $f(x)=\overline{0}$, where 0 is a $2\left(T_{1}-T_{0}\right)-1$ vector of zeros. The algorithm involves making an initial guess at the variables, $x^{0}$, and updating the guess by $x^{i+1}=x^{i}-D f\left(x^{i}\right)^{-1} f\left(x^{i}\right)$, where $D f\left(x^{i}\right)$ is the matrix of partial derivatives of $f(x)$ evaluated at $x^{i}$. The system of equations does not have closed-form expressions for the partial derivatives needed to compute $D f\left(x^{i}\right)$, and so the derivatives have to be evaluated numerically. A solution is obtained when the function, evaluated at the new iterate of $x$, has a maximum error less than some value $\varepsilon$, where $\varepsilon$ is a small number. Although this method of solving a system of nonlinear equations can converge to a solution quickly, this method is not globally convergent and can become stuck away from a zero of $f(x)$ or may not converge at all. The initial guess, $x^{0}$, is important. Further details on the implementation of Newton's method can be found in Press, Flannery, Teukolsky, and Vetterling (2002).

To increase the probability of the algorithm converging to the correct answer, we solve a sequence of models, beginning with a simple version of the model, which we know how to solve, and progressing to the model that we would like to solve. The first model we solve is the one in which TFP, population, and available hours are constant and equal to their average values from 1980 to 2005 , and the tax rates are all zero. The solution to this problem is relatively easy to find. The next model takes TFP, population, available hours, and tax rates to be convex combinations of the constant values used in the initial model and the actual values of TFP, population, available hours, and tax rates from the data. Let $\lambda$ be the weight on the constant values, so that $(1-\lambda)$ is the weight on the values from the data. The algorithm requires repeatedly decrementing $\lambda$ and solving the resulting model, each time using the solution to the model before it as the initial guess. The algorithm proceeds until it solves the case in which $\lambda=0$, which corresponds to the model whose solution we desire.

\section{Appendix B: Construction of Tax Rates}

Computing each tax rate requires data on the revenues collected from the tax and the tax base. The data on the tax bases - consumption, income, and investment-are from the national income accounts, and the data on the tax revenues collected are from the OECD's tax revenue database. A complete description of the data and further details of the tax construction are provided in the Data Appendix at www. greatdepressionsbook.com. 


\section{Effective Consumption Tax Rates}

$R_{c o n, t}=$ revenue from general taxes on goods and services plus excise taxes

$C_{t}=$ consumption of household and nonprofit institutions serving households

$$
\tau_{t}^{c}=\frac{R_{c o n, t}}{C_{t}-R_{c o n, t}} .
$$

\section{Taxes on Household Income}

Taxes on labor and capital are computed in two steps. First, we compute the aggregate marginal tax rate on household income, $\tau_{t}^{h}$; second, we compute the labor and capital tax rates.

\section{Effective Income Tax Rates}

$R_{i n c, t}=$ revenue from taxes on income, profits, and capital gains of individuals

$C E_{t}=$ compensation of employees

$S S E_{t}=$ employers' contribution to social security

$M_{t}=$ household gross operating surplus and mixed income

$\delta K_{t}^{H}=$ household consumption of fixed capital

$$
\tau_{t}^{h}=\mu \frac{R_{i n c, t}}{C E_{t}-S S E_{t}+M_{t}-\delta K_{t}^{H}} .
$$

The progressivity of the income tax system implies that marginal tax rates tend to be larger than the average tax rates we are computing. The term $\mu$ is an adjustment factor that transforms average tax rates to marginal tax rates. Following Prescott (see the paper in this volume), we set $\mu=1.6$.

\section{Effective Labor Tax Rate}

To compute labor and capital income taxes, we must assign the income categories in the data to either capital income or labor income. The problem lies in the category Household Gross Operating Surplus and Mixed Income. Some of this income is earned by capital and some by labor. We make the assumption that capital's share of this income is $\alpha$, as it is in the aggregate production function.

$R_{s o c, t}=$ total social security contributions

$R_{\text {pay }, t}=$ taxes on payroll and workforce

$C E_{t}=$ compensation of employees

$S S E_{t}=$ employers' contribution to social security

$M_{t}=$ household gross operating surplus and mixed income

$\delta K_{t}^{H}=$ household consumption of fixed capital 
$T_{t}=$ taxes less subsidies, as measured in the national accounts

$Y_{t}=$ gross domestic product

$$
\tau_{t}^{\ell}=\frac{\tau_{t}^{h}\left(C E_{t}-S S E_{t}+(1-\alpha)\left(M_{t}-\delta K_{t}^{H}\right)\right)+R_{s o c, t}+R_{\text {pay }, t}}{(1-\alpha)\left(Y_{t}-T_{t}\right)}
$$

\section{Effective Capital Tax Rates}

$\delta K_{t}=$ total consumption of fixed capital

$\delta K_{t}^{H}=$ household consumption of fixed capital

$R_{\text {corp }, t}=$ taxes on income, profits, and capital gains of corporations

$R_{\text {prop }, t}=$ recurrent taxes on immovable property

$R_{f i n, t}=$ taxes on financial and capital transactions

$$
\tau_{t}^{k}=\frac{\tau_{t}^{h} \alpha+\left(M_{t}-\delta K_{t}^{H}\right) R_{c o r p, t}+R_{p r o p, t}+R_{f i n, t}}{\alpha\left(Y_{t}-T_{t}\right)-\delta K_{t}} .
$$

\section{Note}

Conesa gratefully acknowledges the support of the Barcelona Economics Program of CREA, the Ministerio de Educación y Ciencia under grant SEJ2006-03879, and the Generalitat de Catalunya under grant 2005SGR00447. Kehoe and Ruhl gratefully acknowledge the support of the National Science Foundation under grant SES-0536970. We thank Mark Gibson and John Dalton for excellent research assistance.

\section{References}

Böckerman, Petri, and Jaakko Kiander. 2002a. Determination of average working time in Finland. Labour 16 (September): 557-68.

. 2002b. Labour markets in Finland during the great depressions of the twentieth century. Scandinavian Economic History Review 50 (2): 55-70.

Chakraborty, Suparna. 2006. Modeling sudden stops: The role of preferences. Manuscript. Baruch College, City University of New York.

Chari, V.V., Patrick J. Kehoe, and Ellen R. McGrattan. 2005. Sudden stops and output drops. American Economic Review, Papers and Proceedings 95 (May): 381-87.

Conesa, Juan C., and Timothy J. Kehoe. 2007. Productivity, taxes, and hours worked in Spain, 1970-2005. Manuscript. University of Minnesota. 
Correia, Isabel, João Neves, and Sergio Rebelo. 1995. Business cycles in a small open economy. European Economic Review 39 (June): 1089-1113.

Cummins, Jason, and Gianluca Violante. 2002. Investment-specific technical change in the U.S. (1947-2000): Measurement and macroeconomic consequences. Review of Economic Dynamics 5 (April): 243-84.

Gollin, Douglas. 2002. Getting income shares right. Journal of Political Economy 110 (April): 458-74.

Gordon, Robert J. 1990. The measurement of durable goods prices. Chicago: University of Chicago Press.

Gorodnichenko, Yuriy, Enrique Mendoza, and Linda L. Tesar. 2007. Trade and transition dynamics in the Finnish depression. Manuscript. University of Michigan.

Greenwood, Jeremy, Zvi Hercowitz, and Per Krusell. 2000. The role of investment-specific technological change in the business cycle. European Economic Review 44 (January): 91-115.

Hansen, Gary D., and Edward C. Prescott. 1995. Recursive methods for computing equilibria in business cycle models. In Frontiers of business cycle research, ed. Thomas F. Cooley, 39-64. Princeton, NJ: Princeton University Press.

Kehoe, Timothy J., and Kim J. Ruhl. 2007. Are shocks to the terms of trade shocks to productivity? Research Department Staff Report 391. Federal Reserve Bank of Minneapolis.

Kiander, Jaakko. 2004. The evolution of the Finnish model in the 1990s: From depression to high-tech boom. Discussion Paper 344. Government Institute for Economic Research (VATT).

Kiander, Jaakko, and Pentti Vartia. 1996. The great depression of the 1990s in Finland. Finnish Economic Papers 9 (Spring): 72-88.

Koskela, Erkki, and Roope Uusitalo. 2004. Unintended convergence: How Finnish unemployment reached the European level. Discussion Paper 188. Labour Institute for Economic Research.

Ljunge, Martin, and Kelly S. Ragan. 2004. Who responded to the tax reform of the century? Manuscript. University of Chicago.

Mendoza, Enrique G., Assaf Razin, and Linda Tesar. 1994. Effective tax rates in macroeconomics: Cross-country estimates of tax rates on factor incomes and consumption. Journal of Monetary Economics 34 (December): 297-323.

Ohanian, Lee, Andrea Raffo, and Richard Rogerson. 2006. Long-term changes in labor supply and taxes: Evidence from OECD countries, 1956-2004. Working Paper 12786. National Bureau of Economic Research.

Press, William H., Brian P. Flannery, Saul A. Teukolsky, and William T. Vetterling. 2002. Numerical recipes in $\mathrm{C}++$ : The art of scientific computing. Cambridge: Cambridge University Press.

Ragan, Kelly S. 2005. Taxes, transfers, and time use: Fiscal policy in a household production model. Manuscript. University of Chicago.

Rebelo, Sergio. 1991. Long-run policy analysis and long-run growth. Journal of Political Economy 99 (June): 500-521. 
Depression in Finland in the 1990s

Conesa, Kehoe, Ruhl

Rogerson, Richard. 2007. Taxation and market work: Is Scandinavia an outlier? Working Paper 12890. National Bureau of Economic Research.

Ruhl, Kim J. 2004. The international elasticity puzzle. Manuscript. University of Texas at Austin. 
